\title{
THE ROLE OF SOCIAL SUPPORT SOURCES IN ALLEVIATING ACADEMIC CHALLENGES FACING STUDENTS OF THE FACULTY OF LAW SOHAR UNIVERSITY SULTANATE OF OMAN

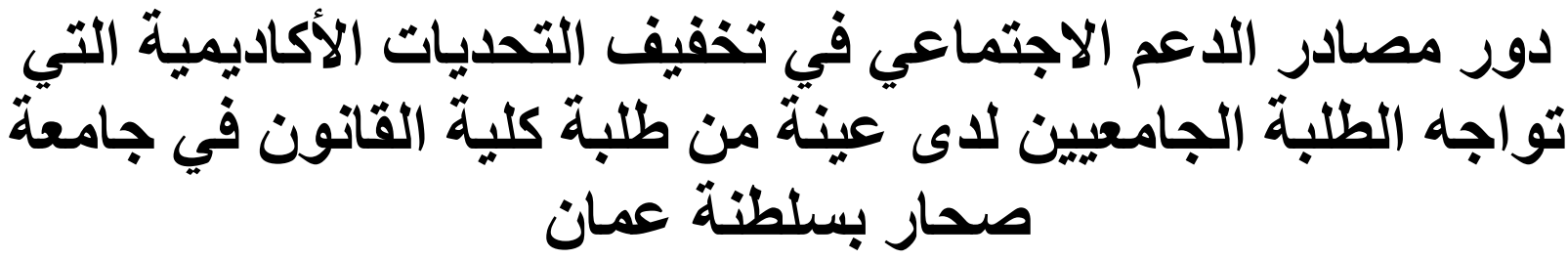

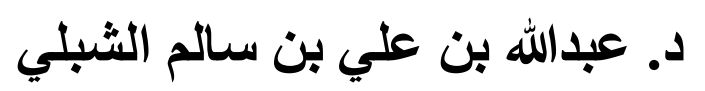

Abdullah Bin Ali Bin Salim Al Shibili

Asst. Prof. Dr., Faculty of Law, Suhar University, Sultanate of Oman, dr342@hotmail.com

\begin{abstract}
This quantitative research discusses the academic challenges facing students at the College of Law at Sohar University, and the role of social support sources in mitigating them. The student is exposed to many challenges that may negatively affect his academic achievement, including the psychological resulting from the conditions of social and family upbringing, and university attitudes represented by the faculty and the university environment. So, the research aims, Discussing the academic challenges facing students, and the role of social support sources from family, friends, mentors, and colleagues in alleviating them. The analytical descriptive approach was adopted, and the relational descriptive methodology represented the research community, so the College of Law's students were (483) male and female students, the sample amounted to (48) male and female students. The researcher designed two questionnaires, the first for academic challenges, consisting of (27) statements distributed over three axes, and the second for social support means of (35) statements distributed on four axes. Descriptive statistical approach and multiple linear regression analysis were adopted. The research reached the following results: Students face several challenges. Related to the professor, related to the academic courses, and those pertaining to the student. Social support sources are of particular importance in mitigating challenges and contributing to the student's sense of psychological stability that increases the level of academic achievement. The research came out with a set of recommendations.
\end{abstract}

Keywords: social support, sources of support, academic challenges.

$$
\text { الملخص }
$$

يناقش هذا البحث الكمي، أبرز التحديات الأكاديمية التي تواجه طلبة كلية القانون في جامعة صحار، ودور

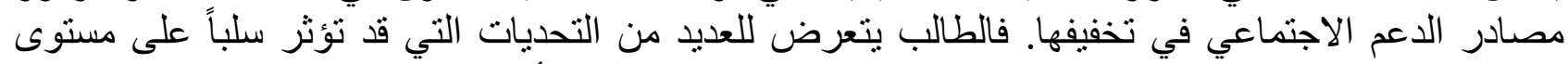

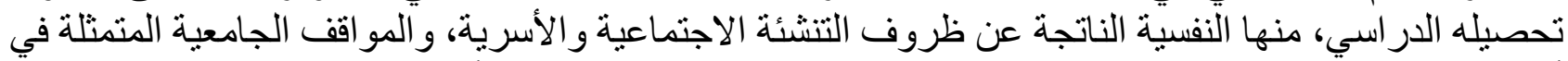
أعضاء هيئة التدريس والبيئة الجامعية. لذا يهدف البحث؛ مناقشة التحديات الأكاديمية التي تو اجه الطلبة، ودور التئه 
مصادر الدعم الاجتماعي من الأسرة، الأصدقاء، المرشد، والزملاء في تخفيفها. اعتمد الباحث المنهج الوصفي

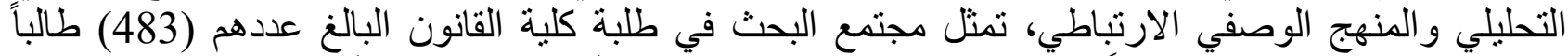
وطالبة، بلغت العينة (48) طالباً وطالبة. صمم الباحث استبانتين، الأولى للتحديات الأكاديمية من (27) عبارة

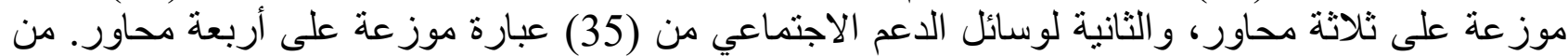

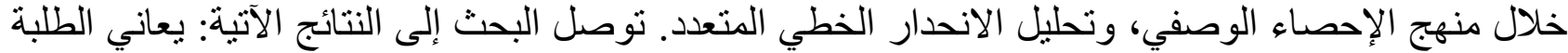

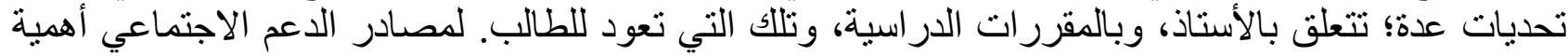
خاصة في تخفيف التحديات، وتساهم في شعور الطالب بالاستثقرار النفسي؛ مما يزيد من مستوى تحصيله

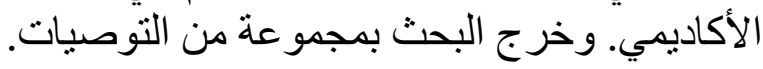

كلمات مفتاحية: الدعم الاجتماعي، مصادر الاعم، التحديات الأكاديمية.

\section{المقدمة:}

تساهم مؤسسات التعليم العالي في تطوير الأفراد بمختلف شرائحهم عموماً، والطلبة الجامعيين على وجه

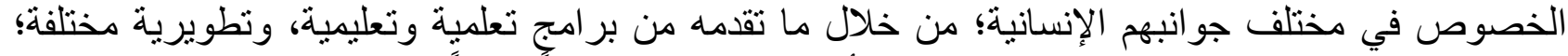

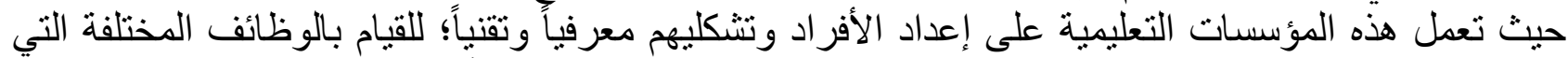

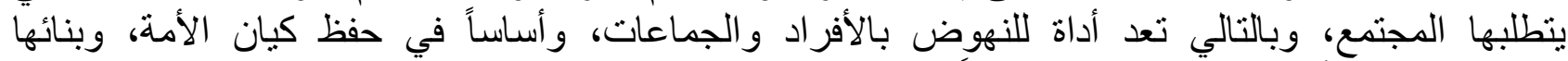

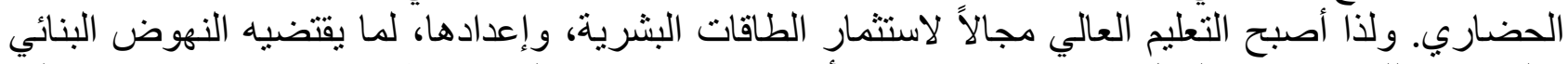

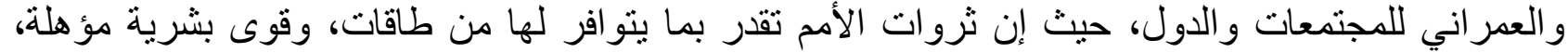

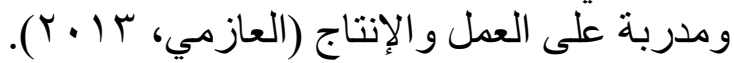

وتعتبر مؤسسات التعليم العالي البيئات التربوية والتنظيمية التي بتلقى فيها الطالب تعلمه، وتعليمه، ولها الأثر

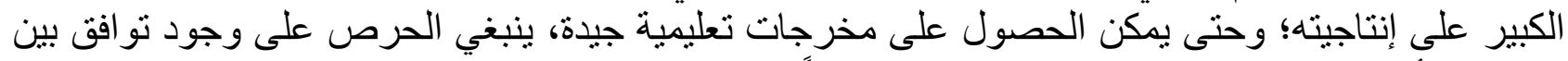

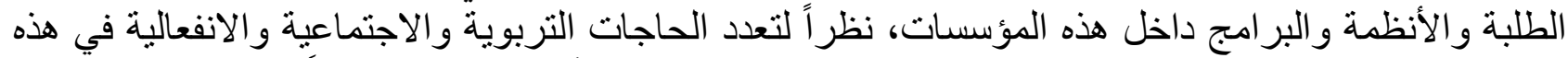

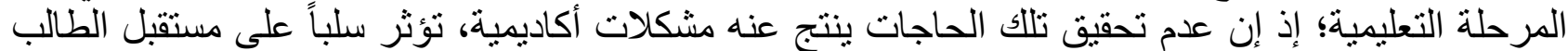

الاجتماعي والنفسي و الأكاديمي (Senel, Consuelo, Robin, \& Stewart, 2001).

وتو اجه الطالب بالمرحلة الجامعية العديد من التحديات، والتي تؤدي في غالبيتها إلى تعثر مسيرته الأكاديمية،

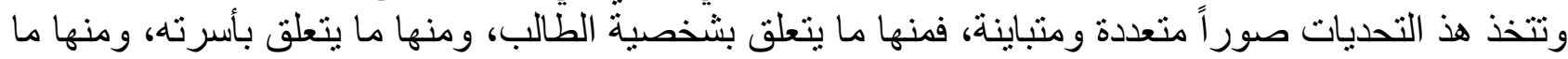

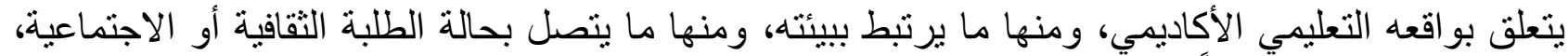

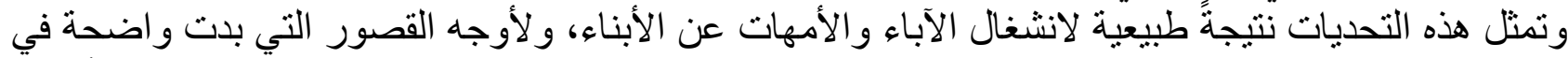

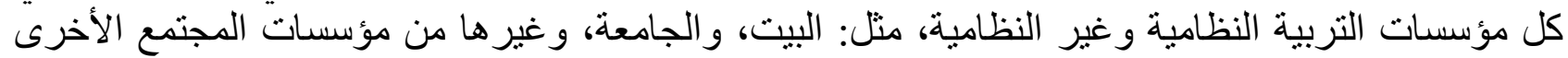

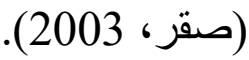

ويقصد بالتحديات الأكاديمية (Academic challenges) في هذا البحث بصورة إجرائية: التحديات المتعلقة

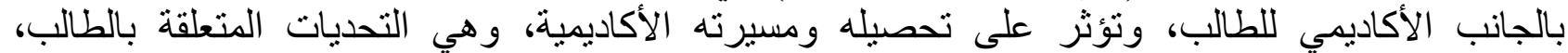

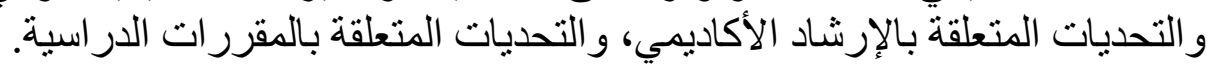

ولعل المرحلة الجامعية هي من بين أهم المراحل التي يحتاج فيها الطالب إلى المزيد من الدعم و المساندة

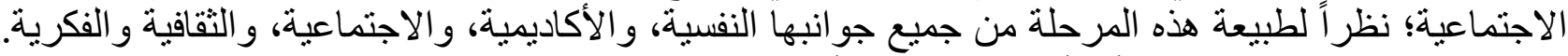

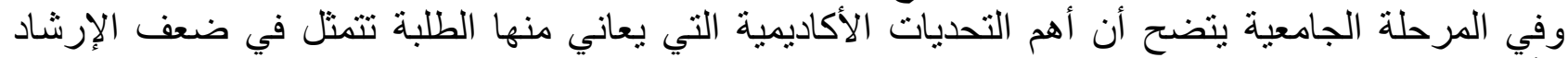

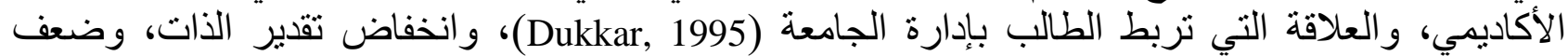
المهار ات الأكاديمية، و عدم القدرة على إدارة الوقت (Kenneth, 1995) وكذللك أساليب التدريس التقليدية و غير

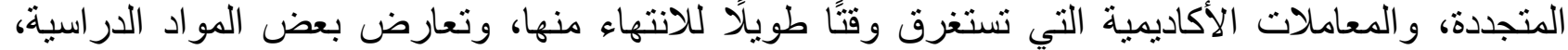

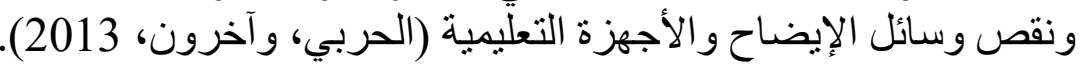
و الطالب الجامعي العماني كسائر الطلبة العرب، تواجهه العديد من التحديات الأكاديمية، وخاصة تلك التي 
تو اجهه منذ بداية دخوله الجامعة؛ نظر اً لاختلاف نمط الحياة اليومية التي اعتادها في مر احل حياته الدر اسية التي

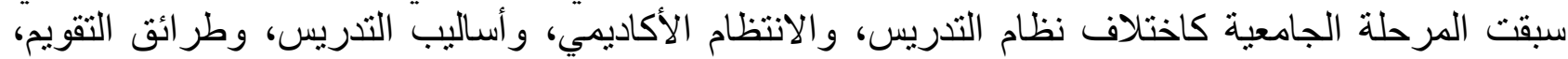

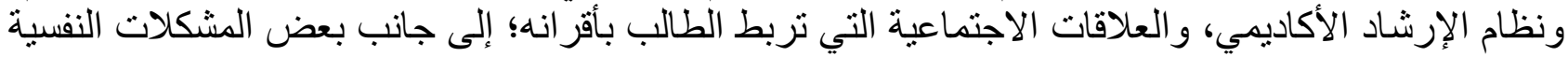

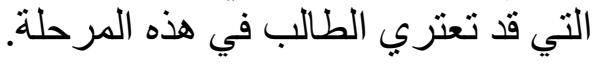
مشكلة البحث:

يتعرض الطالب في مرحلة الدراسة الجامعية إلى العديد من العوامل التي قد تؤثر عليه؛ والتي بدورها قد تؤثر

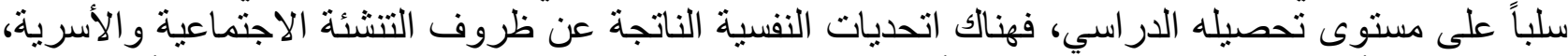

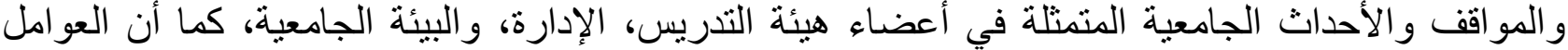
الاجتماعية و المشاكل الأسرية لها تأثير و اضح على على مستوى تحصيل الطلبة (الزهر هراني، 0 . . ب).

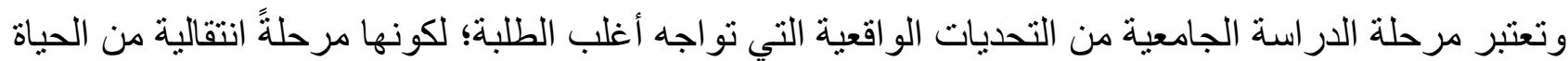

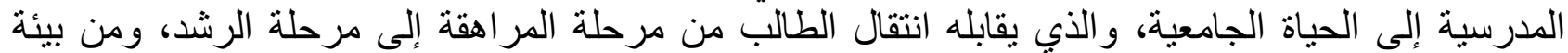

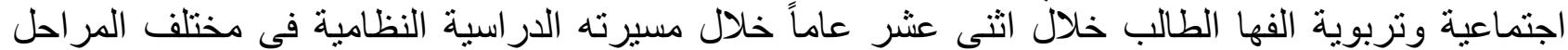
الدر اسية عنها الفرد صورة ما، إلى بيئة اجتماعية، ودر اسية يشهد فيها كثير اً من التغيرات النمائية كالتغيرات

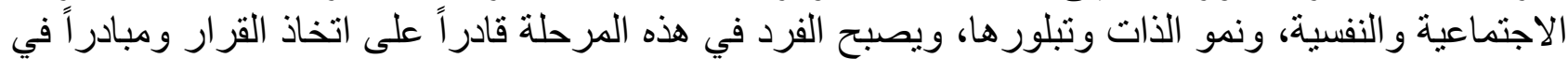

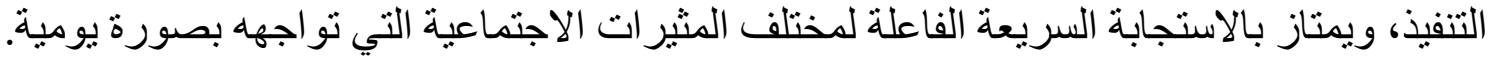
وبناءً على ما سبق فقد جاء البحث الحالي لتسليط الضوء على أبرز التحديات التي تواجه الطالب في مرحلة در استه الجامعية، ودور وسائل الدعم الاجتماعي في التخفيف من تلك التحديات ليعبر الطالب من هذه المرحلة وقد حقق الأهداف و الغايات التي يسعى لتحقيقها من خلائل الته در استه الجامعية. و إجمالاً يمكن القول أن مشكلة البحث الحالي تتحدد في الوقوف على التحديات الأكاديمية التي قد تواجه الطلبة الجامعيين ودور مصادر الدعم الاجتماعي في تخفيفها لدى عينة من طلبة كلية القانون في جامعة صحار بسلطنة عمان. أهداف البحث:

تتحدد أهداف البحث الحالي في الهدف الرئيس الآتي: تحديد العلاقة التحديات الأكاديمية التي تواجه طلبة كلية القانون في جامعة صحار ودور مصادر الاعم الاجتماعي في تخفيفها الوقوف على مدى وجود فروق دالة إحصائياً بين مصادر الدعم الاجتماعي ودورها في تخفيف التحديات

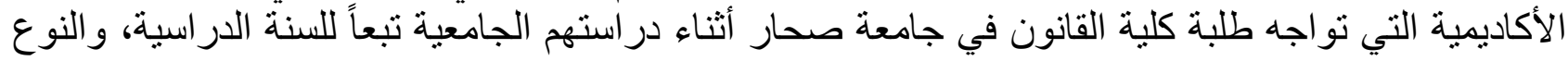
الاجتماعي. منهج البحث: المنهج المستخدم في البحث الحالي هو المنهج الوصفي التحليلي، والذي يعد من أنسب المناهج ملاعمة لمثل هذه التها البحث، كما تم استخدام المنهج الوصفي الارنباطي؛ وذللك للتعرف على التى العلاقة بين التحديات الأكاديمية، ودور

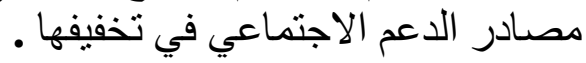
الإطار النظري:

يعتبر مفهوم الدعم الاجتماعي من المفاهيم التي لقيت اهتماماً كبيراً ليس في ميدان علم النفس التربوي فحسب؛ بل في ميادين علم النفس الإرشّادي و العيادي، ورعلم الإئم النفس الاجتماعي، و علم النفس الصناعي. ويثير ملكوش (2000) إلى أن "فكرة تأثثير الجماعة على الاتجاهات و السلوكيات معروفة جيداً، فعلى سبيل

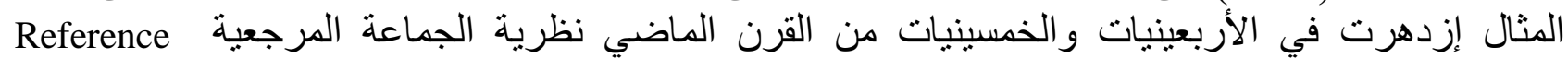
(Group) يتم من خلاله تشكيل الاتجاهات و السلوكيات". وتفترض هذه النظرية أن الناس يختارون أناساً مثلهم للمقارنة 
حيث تكون المعلومات عن الناس الذين يشبهونهم أكثر فائدة للذات.

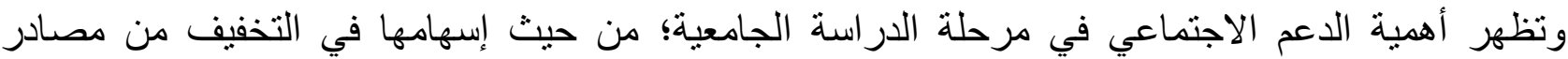

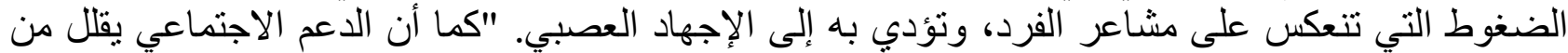

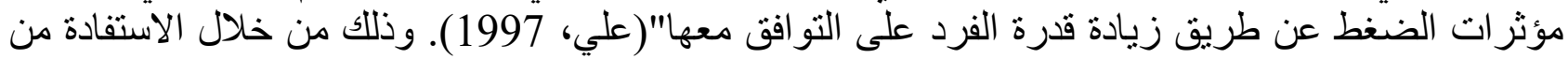

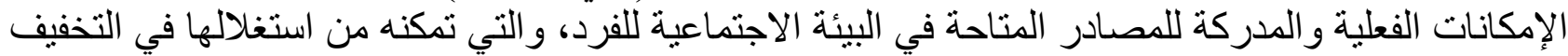

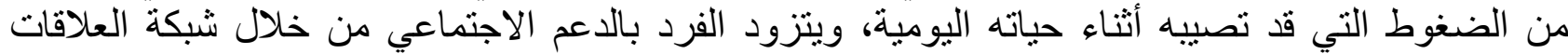

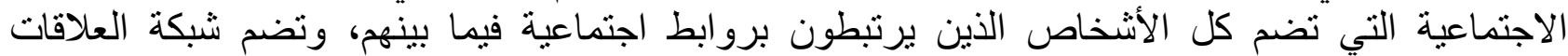
الاجتماعية الأسرة، وزملاء العمل، والأصدقاء؛ حيث يتكون مفهوم الدعم الاجتماعي من عنصرئ بلاعين أساسيين:

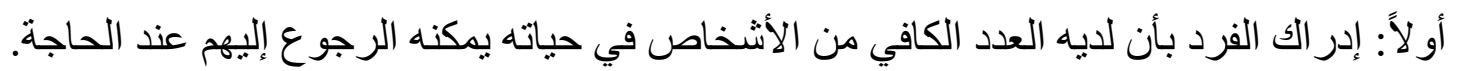

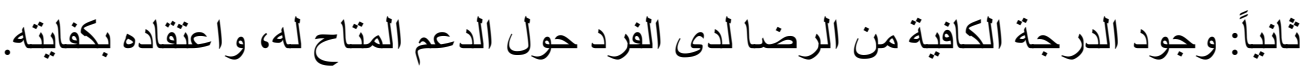

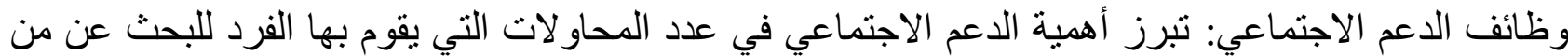

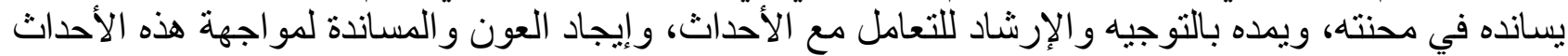

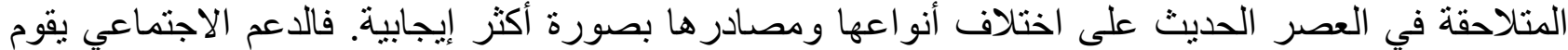
بوظيفتين أسأسيتين لهما علاقة بالضغوط الدئ الدراسية: الأولى: هي الوظيفة الوقائية ضد التأثثر ات السلبية للضغوط على الصحة.

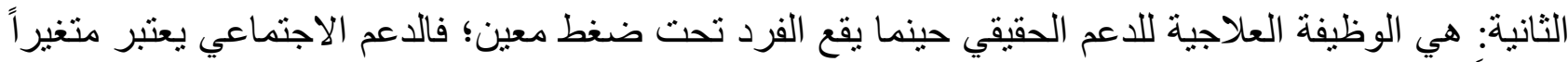

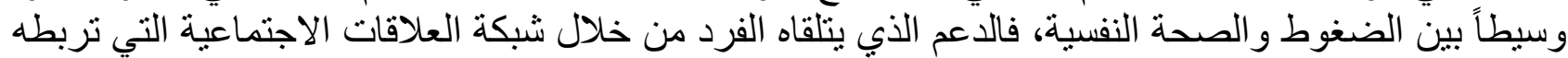

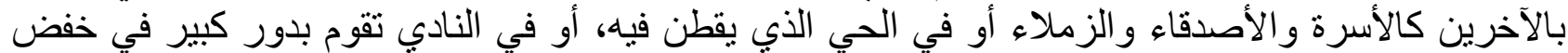

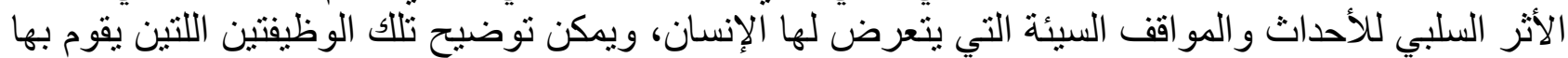

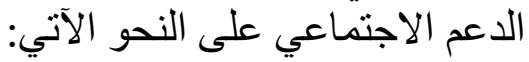

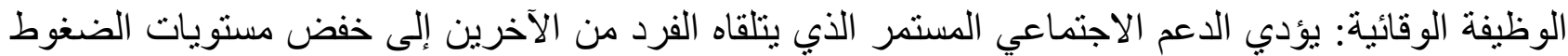

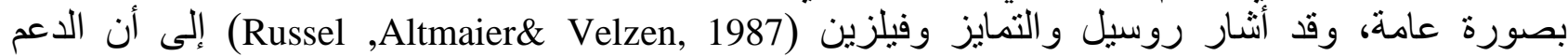

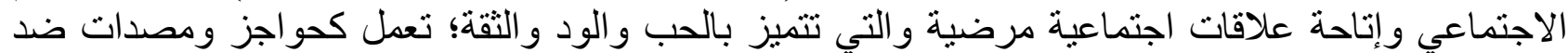

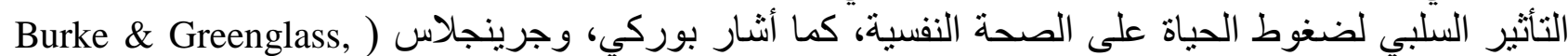

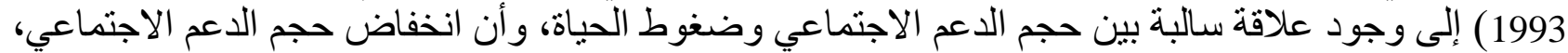

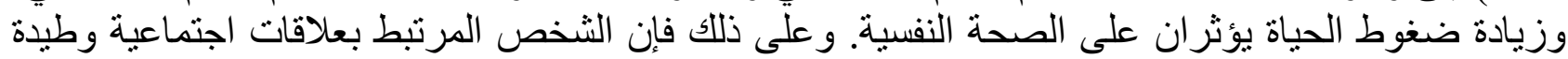
سوف تؤدي به إلى الثعور بالر احة النفسية و الرضا الونية الوظيفي.

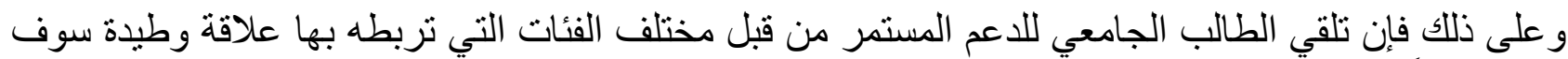

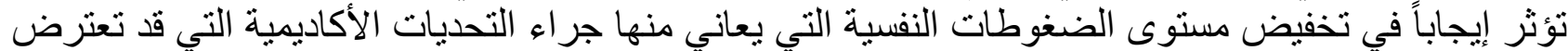

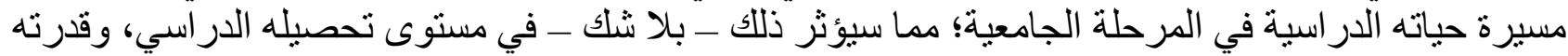
على تحقيق التو ازن الداخلي بينه وبين المحيط الذي الذي يعيش فيه في صورة أكثر ديناميكية.

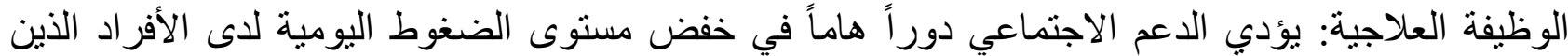

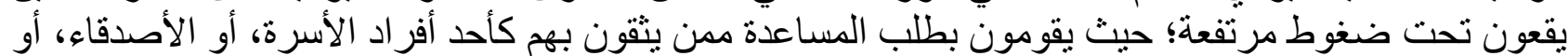

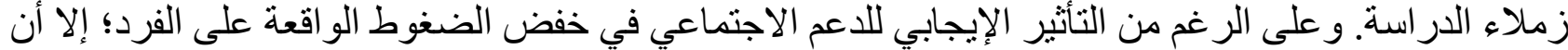

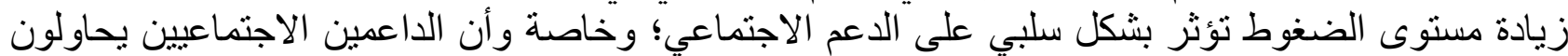
الابتعاد عن الأفر اد الذين يقعون تحت ضغنوط عالية" (Cecil \& Forman, 1990).

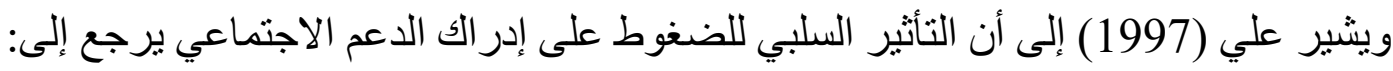
ـ ـ أن الضغوط تشكل مز اجاً سلبياً قد يجعل الآخرين يبدون أقل جاذبية و إيجابية. - ـ أن الظروف اليومية الضاغطة قد تنقص الانتماء الو اقعي مع الآخرين بسبب الخوف من الظهور بطريقة غير الخائ 
مرغوب فيها.

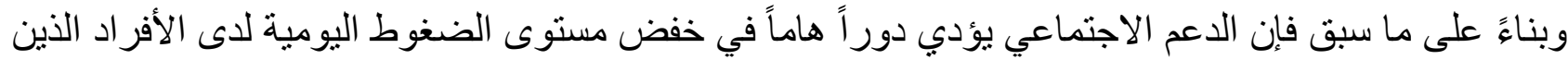

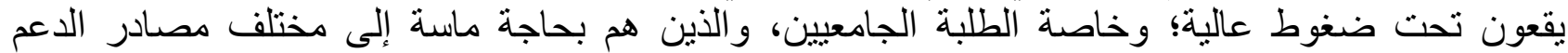

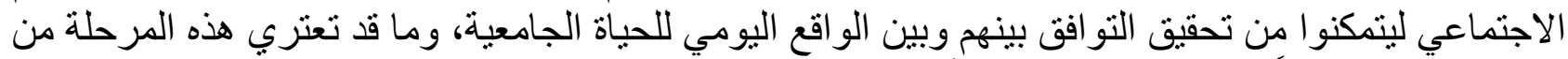

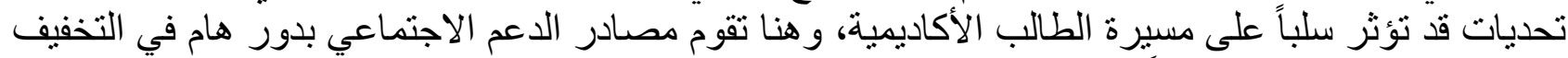

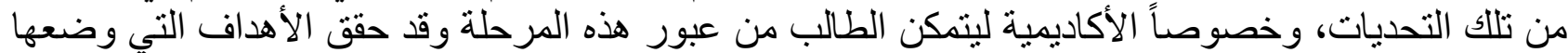

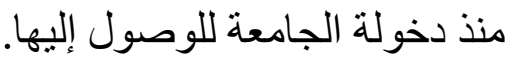

دور الدعم الاجتماعي في أساليب مواجهة ضغوط الحهية الحياة اليومية: يمكن للفرد الاستفادة من الدعم الاجتماعي المقدم له من قبل الآخرين في مواجهة ضغوط الحياة اليومية في جو انب عدة منها:

1 ـ قرته على الاستفادة من الأحداث التي تمر به في حياته المعاصرة وتصحيح مساره، وخاصة تللك المتعلقة بالمستقبل من خلال إعادة النظر في الأهداف التي خطّ لها لها في حياته من خلال الأل التفكير المنطقي المتأني، وتوقع الأحداث التي يمكن أن تقع لله وكيفية مو اجهتها. 2- التفات الفرد إلى اتجاهات وأنشطة أخرى؛ فالدعم الاجتماعي الذي يتلقاه الفرد يؤدي به إلى إعادة تنظيم حياته

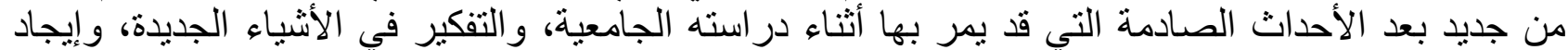

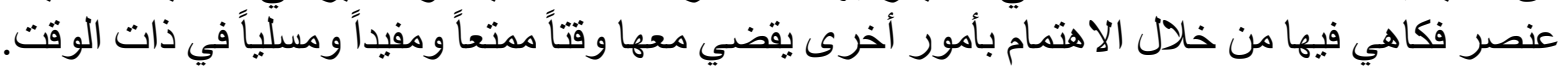
ويشير نورويتش ودانيلس (Norwich \& Daniels, 1997) إلى أن الدعم الاجتماعي الذي يسوده الحب والدفه

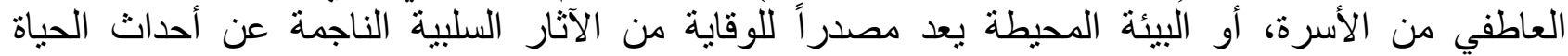
الضاغطة، تساعد الفرد على نسيان الخبرات المؤلمة، ويعيد تكيفه مع عمله. 3ـ العلاقات الاجتماعية: وذلك من خلال إيجاد متنفس عن الأحداث التي مر بها الفرد في توطيد علافته

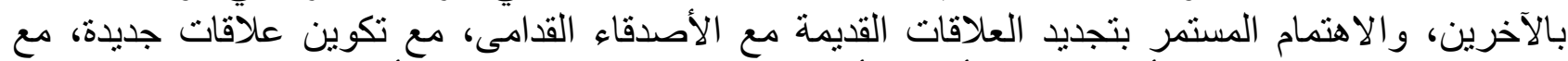
حرصه المستمر على صلة الأرحام، وبقية أفر اد الأسرة؛ كي ينسى الأكريات بهذه الأحداث الصادمة الصادة في حياته. إن الدعم الاجتماعي المقدم من أفراد الأسرة، والرفاق، والزملاء؛ سوف يفضي إلى تقوية شخصية الفردي؛

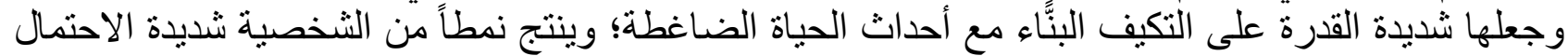
تسنطيع أن تقاوم أحداث الحياة الضاغطة حتى لا تقع فريسة للإضىر ابات النّاء النفسية. ولقد حدد جريفت، وستبتو، وكروبلي (Griffith, Steptoe, Cropley, 1999) قو اعد لذوي الشخصيات التي تعاني من ضغوط الحياة اليومية الضاغطة، ويستطيعون مو اجنتها بكل ثقة وهذه القو اعد: - القدرة على الالتزام: الذي يؤدي إلى النجاح في الحياة اليومية، و إلى سرعة الإنجاز، والترقي الترقي والتفاعل الإيجابي في توطبد علاقات ودية مع الزملاء ومع الأهل و الجيران، لنسيان الخبرات التئ السالبة التي تحكمها أحداث الحياة الضاغطة.

ـ التحدي: وهذه الخاصية تساعد على التكيف السريع في مواجهة أحداث الحياة الضاغطة، وتؤدي إلى تولد مشاعر التفاؤل في تقبل الخبر ات الجديدة. ـ ـ التحكم: ويتمثل في قدرة الفرد على التحكم في الظروف الاجتماعية الخارجية، وفي الظروف التخصية التي تو اجهه حتى يحتفظ بالاتزان الانفعالي، ويتمثل بالصنة فالصة النفسية. تتمية الكفاءة الذاتية: ويتم ذلك من خلال قيام الفرد بتكريس جهده في إنجاز الأعمال و المشرو عات الجديدة التي

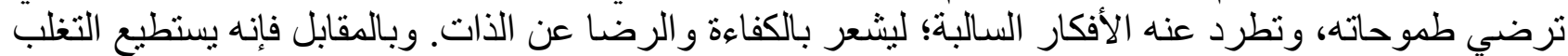

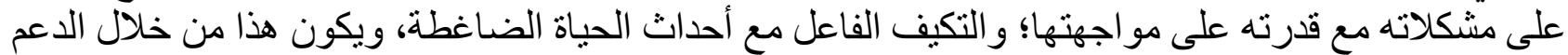
الاجتماعي المستمر من داخل الأسرة التي ينتمي إليها الفرد، أو في بيئة الحياة الجامعية، "والتي التي تتمثل في التي 
إحساسه بالقبول والقيمة و الكفاية، و هذه تعد من الخصائص الثخصية التي تدفعه إلى النجاح في العمل لإرضاء طموحاته، و اكتساب الرضا الرضا عن الذات" (Jarvis, 2002). التحديات الأكاديمية لدى الطلبة الجامعيين:

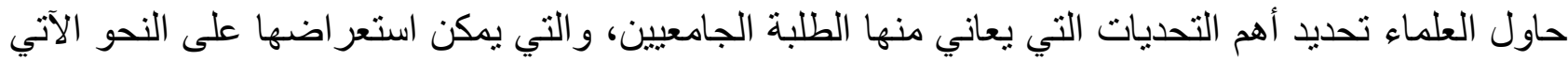

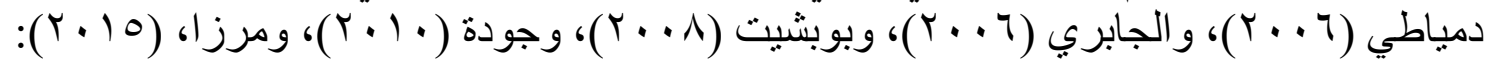

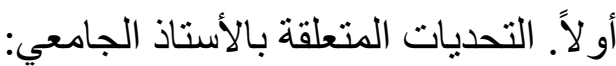

يعتبر الأستاذ الجامعي من أهم الركائز التي تعتمد عليها عمليتي التعليم والتعلم؛ إذ من المأمل أن يكون الأستاذ

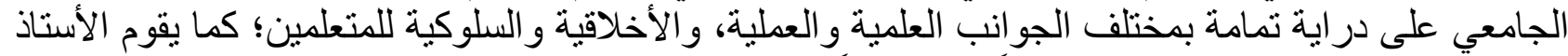

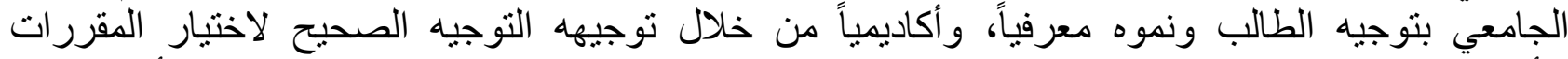

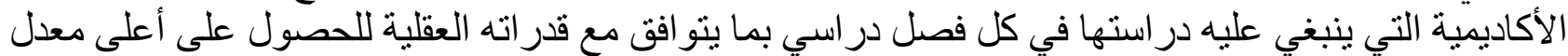

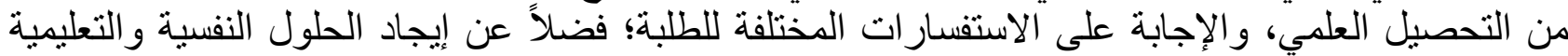

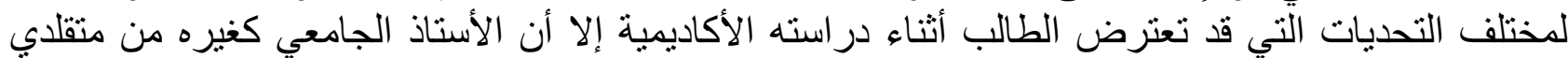

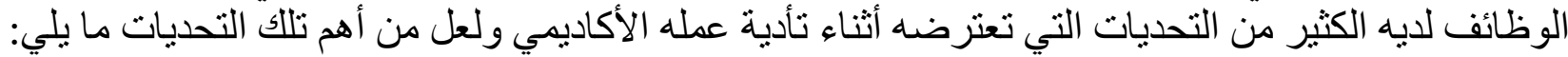
1- قلة اهتمام أستاذ المقرر بتحديد مستوى الطلبة و ما لديهم من معارف ومهار ات في بداية الفصل الدر اسي لكل مقرر در اسي. 2- قلة تمكن بعض أساتذة المقررات الدراسية من المادة التعليمية التي يقومون بتدريسها؛ جراء اختلاف تخصصاتهم الفرعية. 3- غياب التتويع في أساليب التعليم والتعلم أثناء المحاضرة، واعتماد أستاذ المقرر على الإلقاء والتلقين في محاضر اته. 4- قلة مر اعاة أستاذ المقرر للفروق الفردية بين الطلبة، و افتقار أستاذ المقرر القدرة على ضبط السلوكيات غير المر غوب فيها من الطلبة.

5- ضعف قدرة بعض أساتذة المقررات الدراسية على الإجابة عن أسئلة واستفسار ات الطلبة المتعلقة بأنظمة الجامعة في الجانب التعليمي. 6- تأخر بعض أساتذة المقررات عن المحاضرات دون إثعار الطالب بوقت كاف. 7ـ قلة معرفة الطالب، وخاصة المستجد بوجود بر امج الإرشاد الأكاديمي، و أهمية الإرشاد الأكاديمي في توجيهه ومتابعته أثناء وجوده في الجامعة حتى تخرجها

8- قلة اهتمام الأستاذ الجامعي بفهم ظروف الطالب واحتباجاتها وفهم ذاته، ومساعدة الطالب في التخطيط لمستقبله المهني؛ مما يضع الطالب في حيرة وتردد، لقلة فهمه بطبيعة المواد التي ينبغي عليه در استها في كل فله فصل در اسي. 9- قلة فهم الطالب لأهداف ورسالة الكلية، ورسالتها، وأهداف البرامج الدراسية ومتطلباتها من المقررات

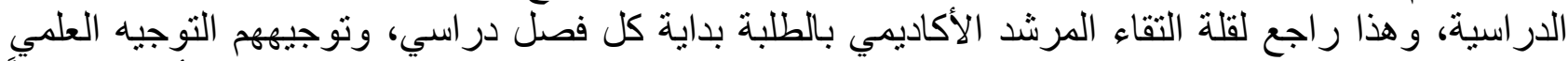

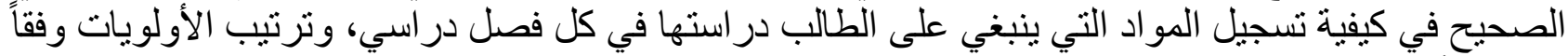
للنظام الأكاديمي المتبع.

10- قلة اهتمام الطالب بالدليل الإرشادي لتوجيه الطالب في بداية التحاقه بالكلية، وذلك راجع إلى قلة توجيه المرشد الأكاديمي بأهمية توجيه الطالب إلى العودة للاليل الإرشادي لاحتو ائه على المئه المعلومات الضرورية للطالب أثناء در استه الجأمعية. 11- ضعف المعلومات المتوفرة على موقع الجامعة حول الإرشاد الأكاديمي، وتجديد المعلومات المتعلقة 
بالدر اسة، و النظم الأكاديمية المستجدة، وتوضيحها بصورة تفصيلية. 12- قلة استخدام الأستاذ الأكاديمي للسجل الأكاديمي الالكتروني الموجود على موقع القبول و التسجيل؛ إذ يتم استخدامه غالباً في حال وجود الطالب تحت الملادظة الأبة الأكاديمية. ثانيا. التحديات المرتبطة بالمقرر ات الدر اسية: تمثل المقررات الدراسية الركيزة الأساسية للطالب الجامعي، والتي من حلالها يتلقى الطالب صنوف العلم

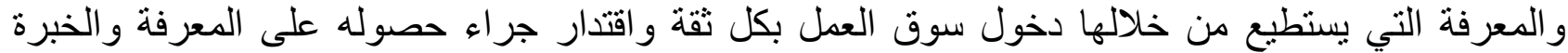

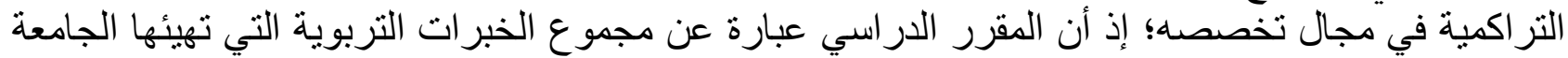
للطلبة داخلها أو خارجها بقصد مساعدتهم على النمو الثامل في جميع جوانب الثخصية الإنسانية العقلية، و التقافية، والدينية، و الاجتماعية، والجسمية، و الفنية؛ مما يؤدي إلى تعديل سلوكهم، ويعمل على تحقيق الأهداف التربوية المنشودة.

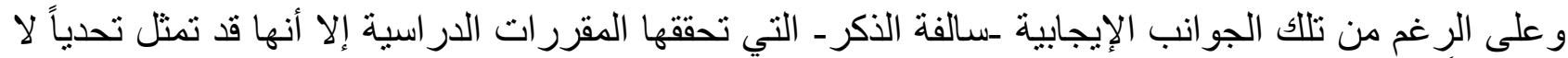
يقل شأناً عن التحديات الأخرى للطالب الجامعي نتيجة لبعض الأسباب، والتي يمكن استعر اضها على النحو الآتي:

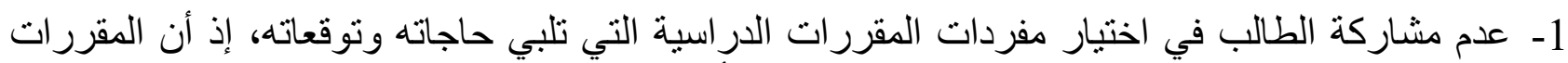
الدر اسية يتم إقر ار ها من قبل إدارة الكلية، وقلما يتم تغيير ها أو تطوير ها، ولا يتم ذللك إلا بعد فترة زمنية قد تمتد لسنوات.

2- صعوبة استيعاب الطالب محتوى بعض المقررات الدراسية؛ نتيجة لكثافتها، وعمق محتواها، وعدم كفاية الوقت أثناء المحاضر ات لفهم المحتوى التعليمي لكل محاضرة. 3- صعوبة استيعاب الطلبة للمحتوى الذي يدرس باللغة الانجليزية، وقلة الأنشطة التعليمية المصاحبة لهذا النوع من المقررات.

4- التركيز على الكتب الدر اسية كمصدر أساسي للتعلم، وقلة نشاطات تعلمية إثرائية لتحسين أداء الطلبة متعلقة بتلك المقرر ات.

5- قلة استخدام الخدمات الالكترونية الحديثة في التدريس، وتوظيفها بصورة صحيحة. 6- قلة معرفة الطالب للأنظمة المقررة في طريقة إعادة در اسة وتأجيل وحذف المقرر ات الدر اسية. 7- اعتماد غالبية أساليب التقويم على قياس مستوى الحفظ والتذكر لدى الطلبة، و إغفال بقية مستويات التعلم الأخرى كالتفسير، و التركيب، والتئة التطبيق، و التقويم.

8ـ قلة معرفة الطالب لنظام الجامعة في التعامل مع الغش في الاختبار ات و الو اجبات، و البحوث و والتقارير؛ فضلاً عن قلة فهم الطلبة للمعايير المتبعة في كيفية تصحيح الواجبات والاختبار ات، والبحوث و التقارير، و الاقتصار

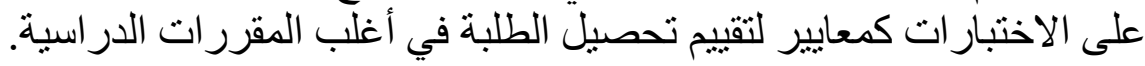
ثالثاً. التحديات المرتبطة بالطالب:

تعد المرحلة الجامعية من أهم المر احل في حياة الطالب الجامعي بسبب ما تضيفه من فرص النما النمو الثخصي

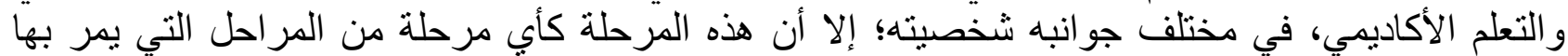

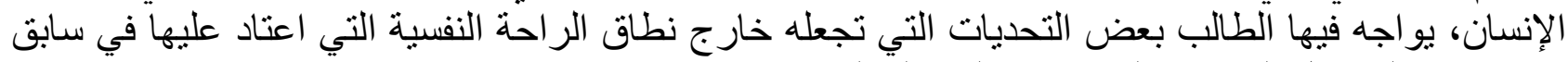
در استه في المر احل الدر اسية التي سبقت المرحلة الجامعية. ويعد دخول الطلبة للمرحلة الجامعية نقلة نوعية في حياتهم؛ نظر اً لما تحمل هذه المرحلة من أهمية في بناء

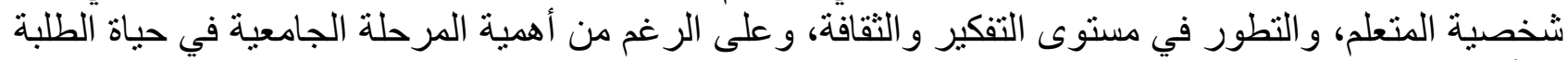

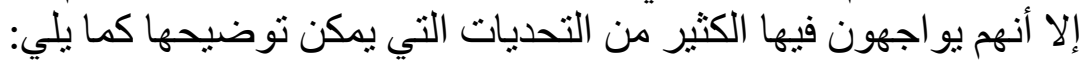


1- شعور الطالب، وخاصة المستجد بعدم التو افق النفسي و الاجتماعي مع الحياة الجامعية؛ مما يؤثر ذلك في قلة

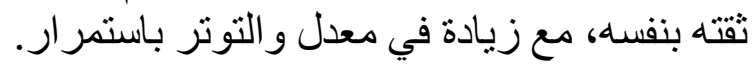
2- قلة توفر الجو الأسري الملائم للار اسة والتحصيل العلمي، ومحدودية دخل الأسرة وانخفاض المئل المستوى

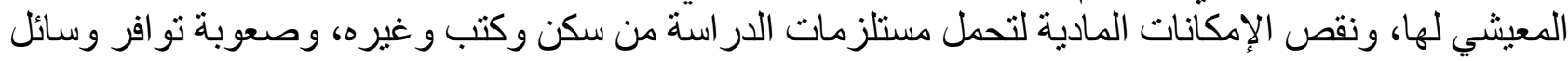

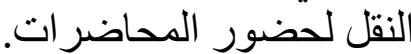

3- في الغالب عدم تناسب التخصص الدراسي لرغبات الطالب الجامعي، إذن قد يدخل الطالب بعض التخصصات دون رغبة حقيقية؛ مما ينعكس ذللك سلباً على تحصيله الأكاديمي. لتهي.

4- ضعف التحصيل الدر اسي في مر احل التعليم العام، و عدم التمكن من مهار ات التعلم الأساسية مثل مهار ات ات التهات

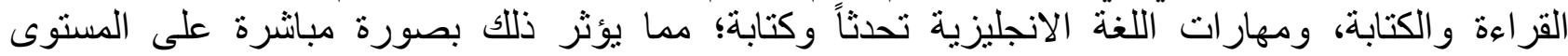
التحصيلي للطالب.

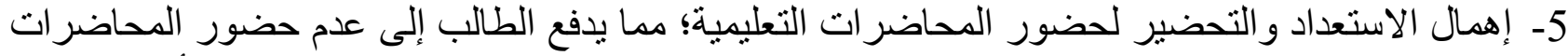
بصورة منتظمة؛ وهذا ما يسمى بالتسرب الإب الدر اسي. فالتسرب من الجامعة يحدث نتيجة للاختيار الأكاديمي غير المناسب، وعدم النجاح في الحد الأدنى من المتطلبات، ومو اضيع غير محفزة. و هناك عدة عو الأل التل للتسرب، منها:

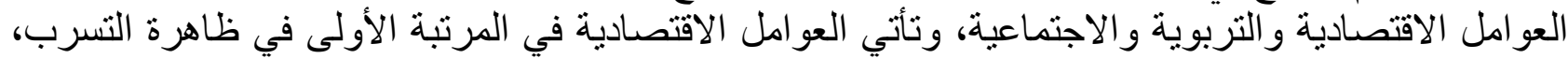

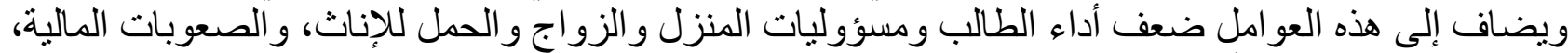

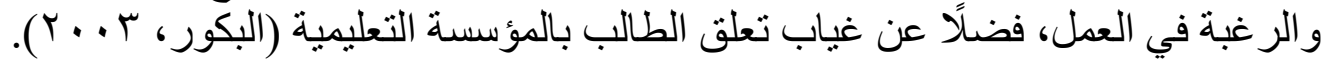
6- اعتماد الطالب على غيره في عمل الواجبات و التقارير؛ و هذا بدونه يؤثر بلا شك في قلة تمكنه من فهم المادة العلمية.

7ـ قلة تمكن الطالب من مهار ات تدوين المذكر ات أثناء حضور المحاضر ات، واعتماده على غيره من الطلبة؛

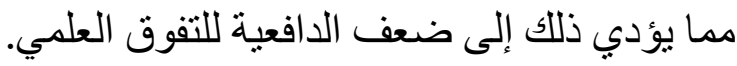

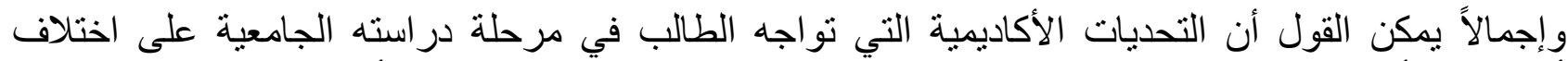

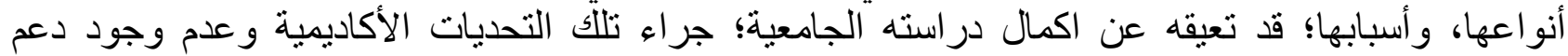

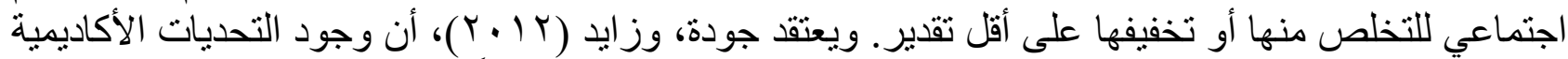

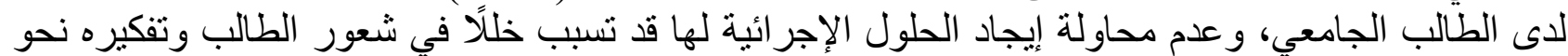

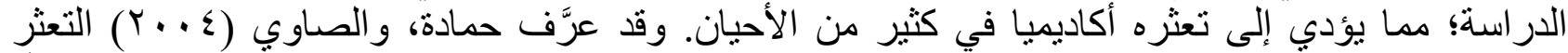

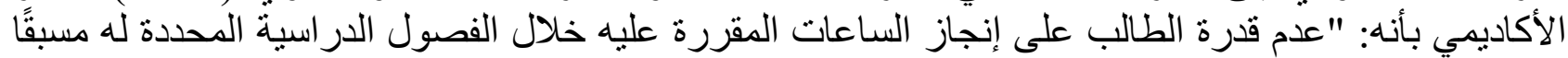

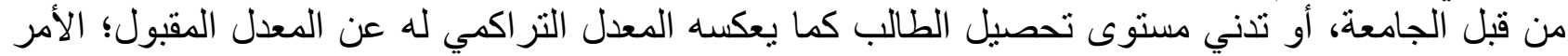

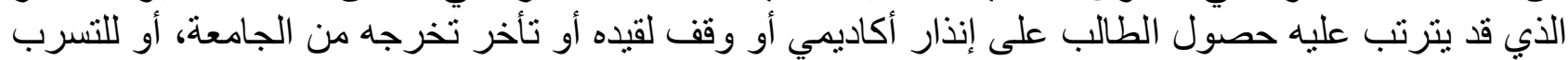
و هو أن ترك مقاعد الدر اسة قبل نهاية المرحلة الجامعية". الار اسات السابقة: أولًا: الار اسات العربية:

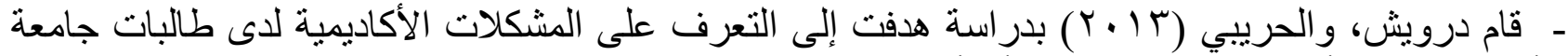

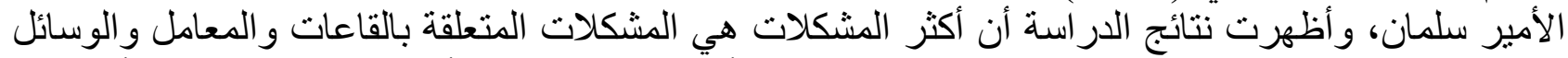

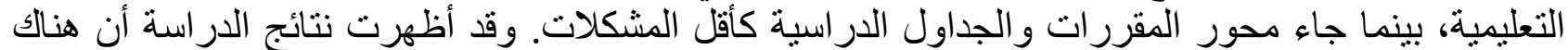

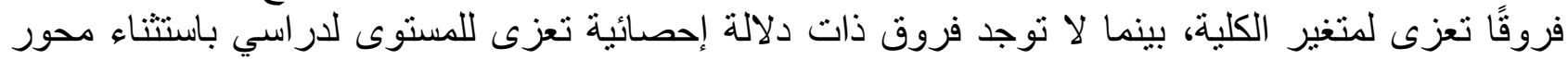
الشبكة التلفزيونية.

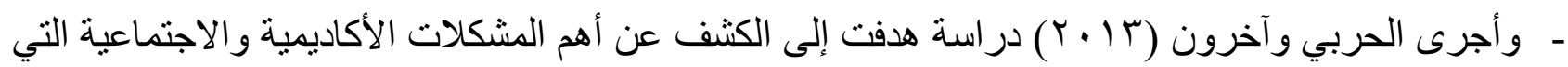

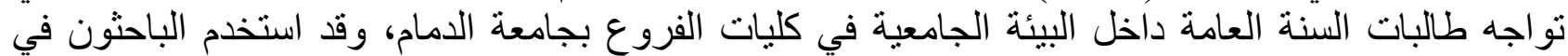
در استهم استبانة تم تطبيقها على عينة عشوائية من طالبات السنة العامة بكليات الفروع، وتوصلت فيلت إلى إلى أن أهم 
المشكلات هي أن أساليب التدريس الحالية تقليدية وغير متجددة، إضافةً لتعارض بعض المواد الإد الدراسية، ونقص

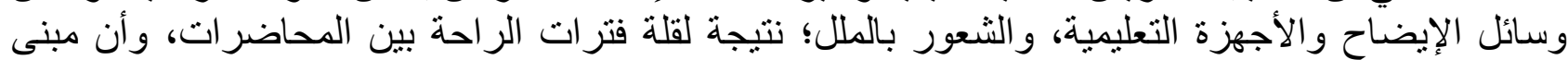
الكلية غير مهيأ للبيئة الجامعية، و عدم وجود أماكن لممارسة الأنشطة المختلفة للطالبات.

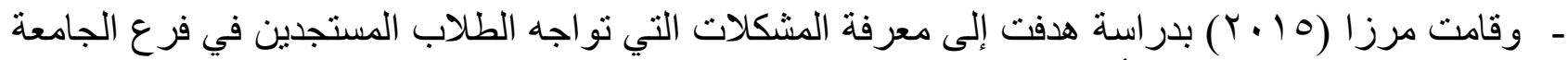

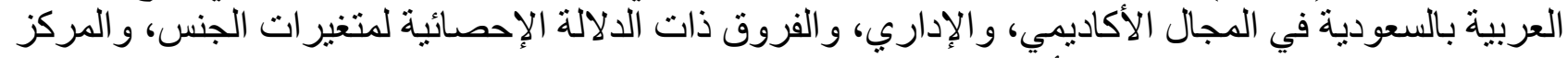

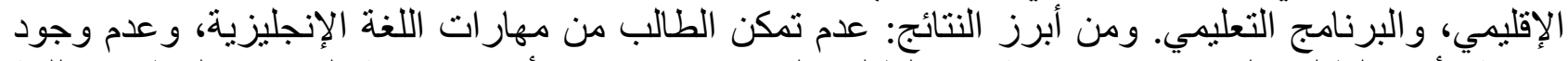
مر اقبة لأداء الطالب المستجد، وصعوبة فهم الطالب المستجد من بعض العض أعضاء هيئة التدريس الناطقين باللغة الإنجليزية، وخوف الطالب من صعوبة أسئلة الاختبار ات، وتسجيل الطالب اسم المقرر دون معرفة اسم أستاذ بـأ المقرر.

ثانياً الدر اسات الأجنبية:

و هدفت در اسة إركان و آخرون (Erkan, et. al, 2012) إلى التعرف على مشكلات الطلبة في الجامعات التركية

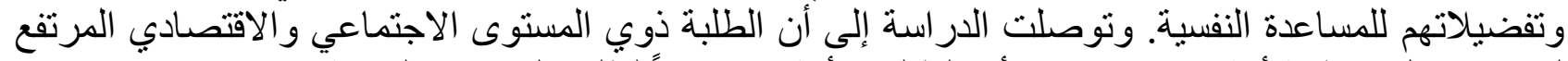

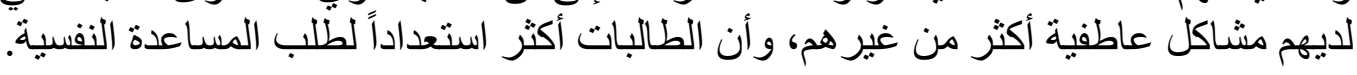
وقام دويجن وجيوللك (Doygun \& Gulec, 2012) بدراسة هدفت إلى التحقق من المشاكل التي تواجه طلبة

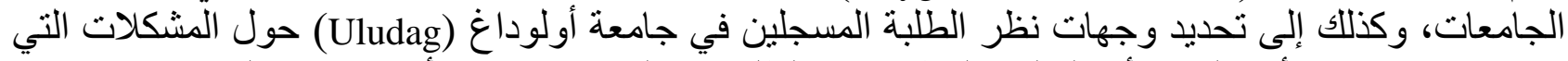

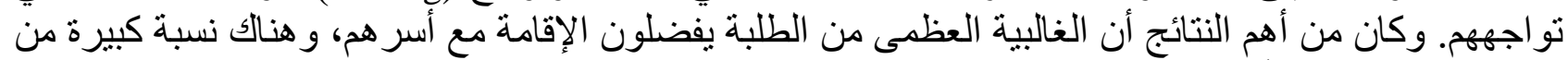

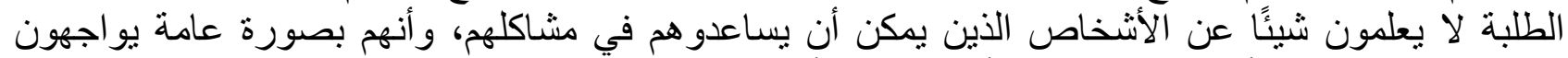

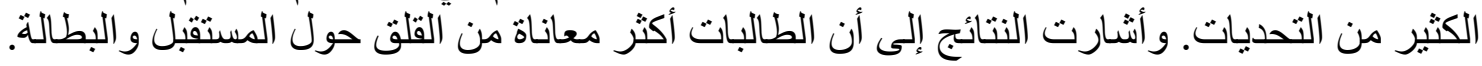

منهج البحث: من:

المنهج المستخدم في البحث هو المنهج الوصفي التحليلي، و الذي يعد من أنسب المناهج ملاعمة لمثل لهذا البحث؛

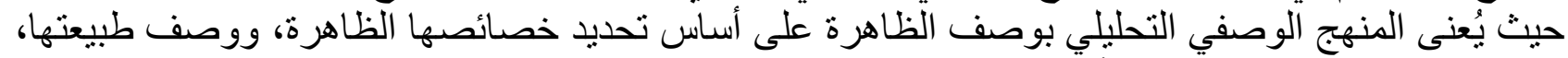
ونوعية العلاقة بين منغيراتها وأسبابها و اتجاهاتها؛ بهدف التحليل والتفسير لهذه البيانات واستخلاص التهات النتائج

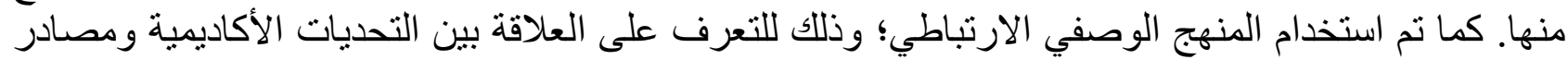
الدعم الاجتماعي التي تعين في تخفيف تلإ الته التحديات.

مجتمع البحث، وعينته:

تمثل مجتمع البحث الحالي في جميع طلبة كلية القانون في جامعة صحار بسلطنة عمان و البالغ عددهم (483)

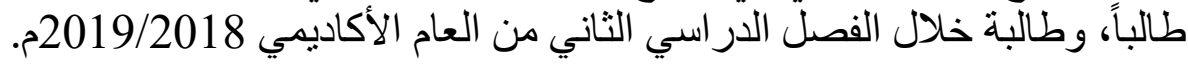
أما العينة فقد تم أخذ عينة عشو ائية مقارها 10\% من طلبة كلية القانون في جامعة صحار بسلطنة عمان؛ حيث بلغت العينة الحالية للبحث الحالي (48) طالباً وطالبة. أداتا البحث:

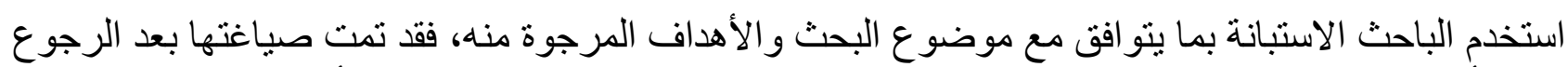

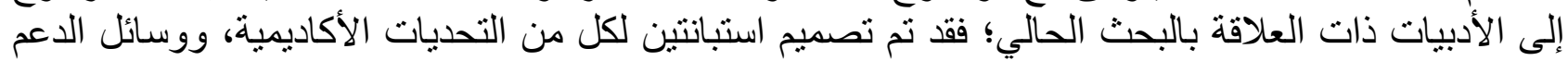
الاجتماعي.

1- استبانة التحديات الأكاديمية: تكونت الاستبانة في صورتها النهائية من (27) عبارة موزعة على محاور ها الثلاثة.

2- وسائل الدعم الاجتماعي: تكونت الاستبانة في صورتها النهائية دن (35) عبارة موزعة على وسائل الدعم الاجتماعي الأربعة. صدق الأداتين: قام الباحث بالتأكد من صدق أداتي البحث من خلال ما يلي: 
أولاً: الصدق الظاهري (الخارجي) للأداتين: قام الباحث بعرض الأداتين على عدد من أساتذة الجامعة، وعلى ضوء ملحوظاتهم تم التوصل إلى الصورة الصورة النهائية للاستبانتين. ثانياً: صدق الاتساق الداخلي للأداتين:

استبانة التحديات الأكاديمية: تم حساب الاتساق الداخلي من خلال معاملات ارتباط المحاور بالقسم الذي تتتمي

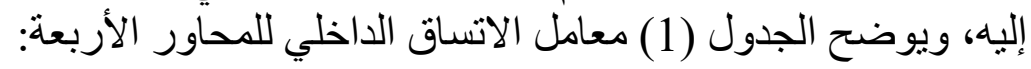
الجدول (1) معامل الاتساق الداخلي للمحاور الأربعة

\begin{tabular}{|c|c|}
\hline & التحديات الأكاديمية \\
\hline معامل الارتباط & نوع التحدي الأكاديمي \\
\hline 0.779 & الأستاذ الجامعي \\
\hline 0.878 & المقرر ات الدر اسية \\
\hline 0.827 & الطالب \\
\hline
\end{tabular}

يلاحظ من خلال الجدول (1) و المتعلق بمعامل الاتساق الداخلي للمحاور الثثلاثة أن قيم معاملات الارتباط بين

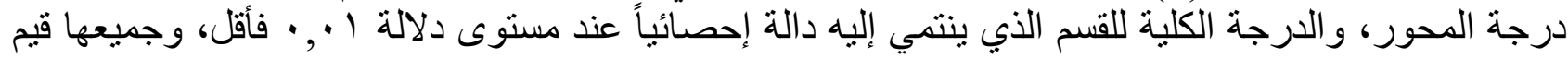

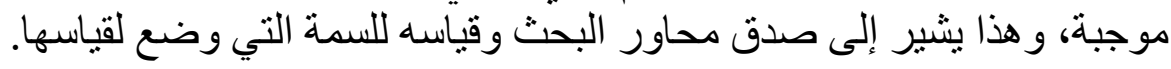
ب. وسائل الدعم الاجتماعي: تم حساب الاتساق الداخلي من خلال معاملات ارتباط الفقرات بالقسم الذبي تتنمي

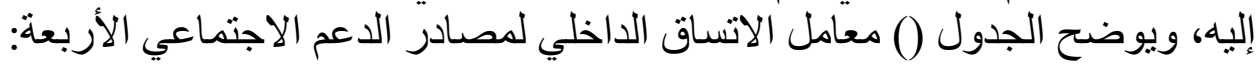
الجدول (2) معامل الاتساق الداخلي لمصادر الدعم الاجتماعي الأربعة

\begin{tabular}{|c|c|}
\hline & مصادر الدعم الاجتماعي \\
\hline معامل الارتباط & نو ع مصدر الدعم الاجتماعى \\
\hline 0.899 & الأسرة \\
\hline 0.870 & الأصدقاء \\
\hline 0.878 & المرشد الأكاديمي \\
\hline 0.727 & زملاء الدر اسة \\
\hline
\end{tabular}

يلاحظ من خلال الجدول (2) والمتعلق بمعامل الاتساق الداخلي لمصادر الدعم الاجتماعي الأربعة أن قيم

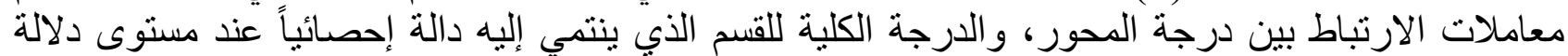

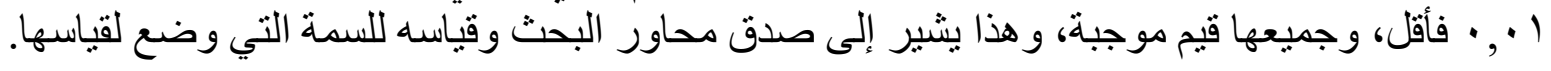
ثبات أداتي البحث: ولقياس مدى ثبات أداتي البحث تم استخدام معادلة ألفا كرونباخ (Cronbach 'Alpha)، للتأكد من ثبات أداتي البحث، وذللك بتطبيق الأداتين المكونتين من (27) مفردة، لاستبانة التحديات الأكاديمية، و (47) مفردة لوسائل

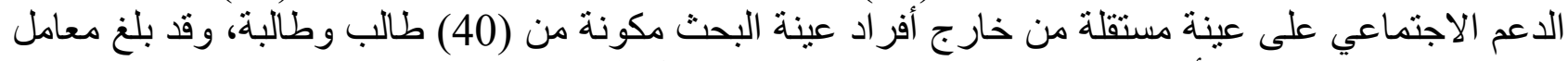

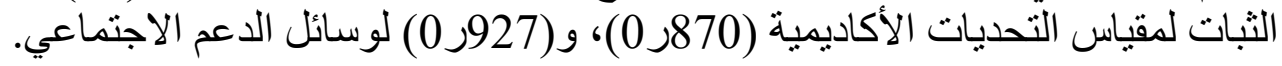
متغير ات البحث: تتضمن متغير ات البحث: ما يلي: • السنة الأكاديمية: (الأولى، و الثانية، و الثالثة، و الر ابعة). • النوع الاجتماعي ( ذكور، و إناث).

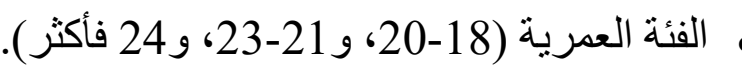
• التحديات الأكاديمية لدى الطلبة: ويحدد إجرائياً بالدرجة التي يحصل عليها الأفراد على المقياس المستخدم لهذا الغرض. • الدعم الاجتماعي للطلبة: ويحدد إجرائياً بالدرجة التي يحصل عليها الأفراد على المقياس المستخدم لهذا 


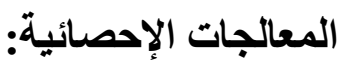

تم استخدام برنامج الرزمة الإحصائية للعلوم الاجتماعية (SPSS) في تحليل البيانات؛ حيث تم استعمال الإجر اءات الإحصائية الآتية: التحليل الوصفي لاستخراج المتوسطات الحسابية، تحليل الانحدار الخطي المتعدد وذللك بعد القيام بعمليات

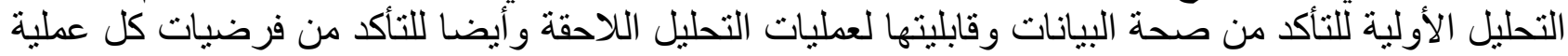
إحصائية على حدة الأنة

\section{نتائج البحث ومناقشتها:}

أولا: التوزيع الطبيعي (Normal Distribution) وتثبير الفرضية الثانية إلى أهية التأكد من أن تكون البيانات موزعة توزيعاء طبيعياء للمتغيرات المستقلة

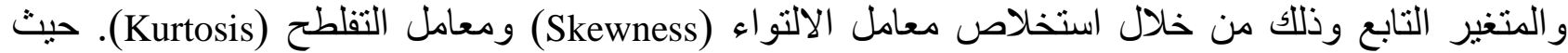

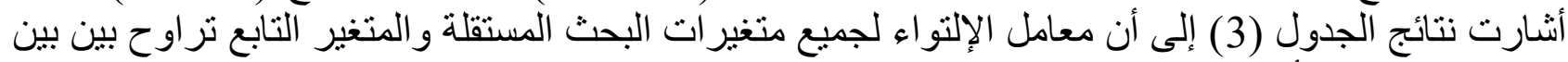

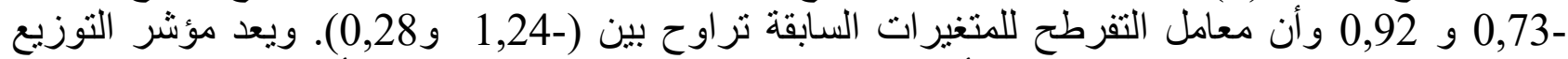

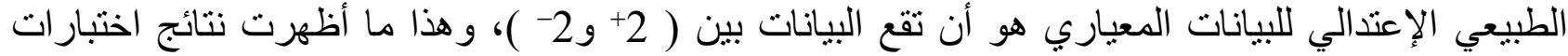

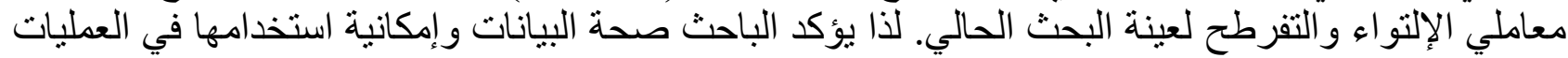

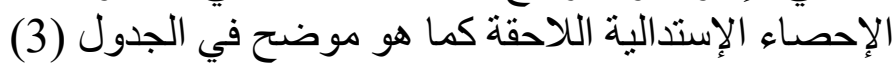
الجدول رقم (3) معامل الالنتواءو التقلطح وكرونباخ ألفا

\begin{tabular}{|c|c|c|}
\hline التفلطح & الالتو اء & العامل \\
\hline$-1,24$ & 0,92 & النوع \\
\hline$-0,92$ & $-0,16$ & الفئة العمرية \\
\hline 0,41 & $-1,27$ & السنة الأكاديمية \\
\hline$-0,10$ & $-0,04$ & الأستاذ الجامعي \\
\hline$-0,16$ & $-0,36$ & المقرر ات الدراسية \\
\hline$-0,93$ & 0,15 & الطالب \\
\hline$-0,86$ & $-0,16$ & الأسرة \\
\hline$-0,16$ & $-0,48$ & الأصدقاء \\
\hline 0,28 & $-0,73$ & المرشد الأكاديمي \\
\hline$-1,16$ & $-0,26$ & زملاء الدر اسة \\
\hline
\end{tabular}

ثالثا: مصفوفة الارتباط Correlations

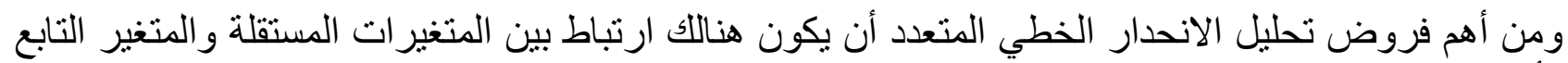

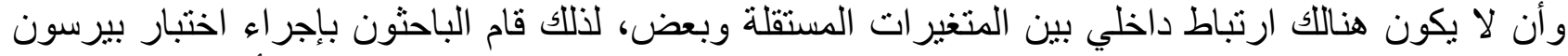

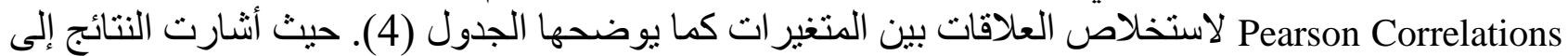
أن العلاقة بين المتغير التابع والمتغيرات التابعة كانت قوية تتراوح بين (-0,46 -0,96) وكانت أعلى الروابط 
متمثلة بين متغير القيادة الإدارية ومتغير الأداء. كما أظهرت النتائج ضعف علاقة الارتباط بين المتغيرات

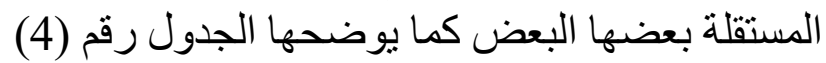
جدول (4) مصفوفة الارتباط بين المتغير ات المستقلة (مصادر الدعم الاجتماعي / النوع/الفئة العمرية/السنة

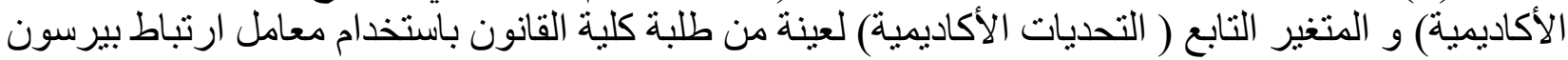

\begin{tabular}{|c|c|c|c|c|c|}
\hline السنة الأكاديمية & العمرئة & النوع & الاجنماعي الدعم & التحديات الأكاديمية & المتغير ات \\
\hline & & & & - & التحديات الأكاديمية \\
\hline & & & - & 0,96 & مصادر الدعم الاجتماعي \\
\hline & & - & $-0,26$ & $-0,30$ & النوع \\
\hline & - & 0,13 & 0,01 & $-0,03$ & الفئة العمرية \\
\hline - & 0,19 & $-0,46$ & 0,12 & 0,16 & السنة الأكاديمية \\
\hline
\end{tabular}

النتائج المتعلقة بالسؤال الأول ومناقشتها:

للإجابة عن السؤال الأول اختار الباحث الانحدار الخطي المتعدد البسيط للتعرف على نوع العلاقة بين متغيرات

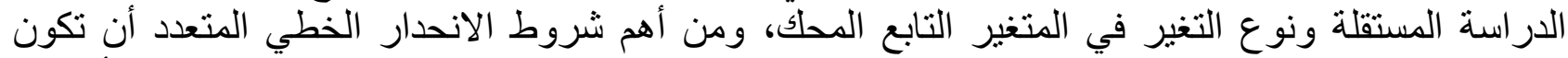

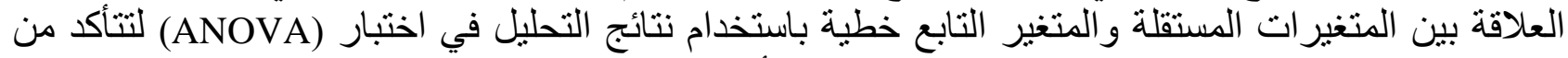

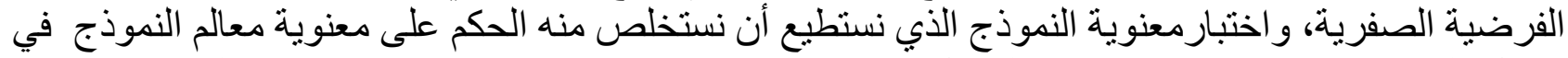
جدول المعاملات. حيث كثفت نتائج التحليل معنوية الفاء النسبية ورفض الفية الفرضية الصفية فئية لذا اتبع الباحثي

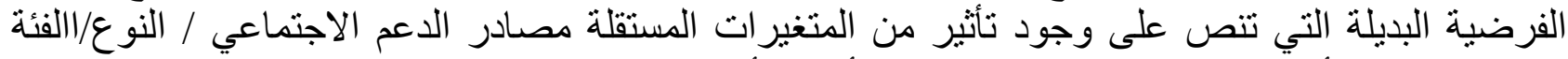

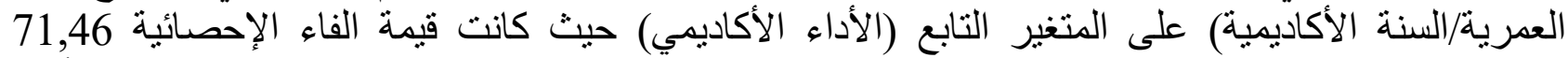

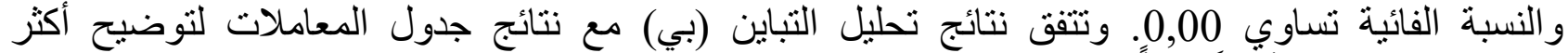
المتغير ات المستقلة تأثتير اً وتتباً بالتغيير المستقبلي للمتغير التابع (المحك).

الجدول(5) تحليل التباين (بي)

\begin{tabular}{|c|c|c|c|c|c|c|}
\hline الفائية & الإحصائي & المربعات & الحرجة & المربعوع & النموذج & النموذج \\
\hline \multirow[t]{3}{*}{0,00} & 71,46 & 3,51 & 4 & 14,05 & الخطي & \multirow{3}{*}{ 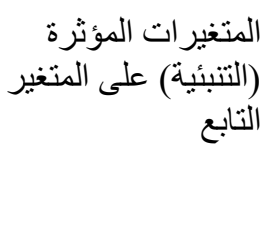 } \\
\hline & & 0,05 & 22 & 1,11 & الخطأ المعياري & \\
\hline & & & 26 & 15,13 & المجموع & \\
\hline
\end{tabular}

تحديد نسبة تفسير المتغير ات المستقلة للمتغير التابع:

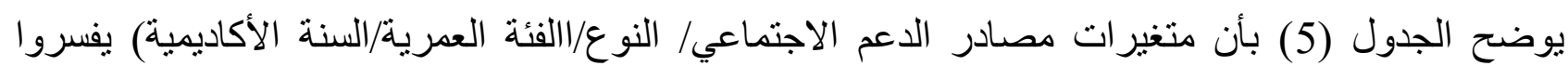

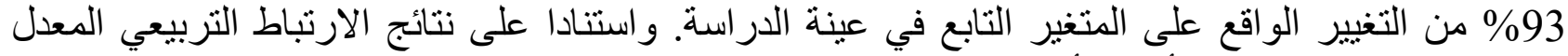

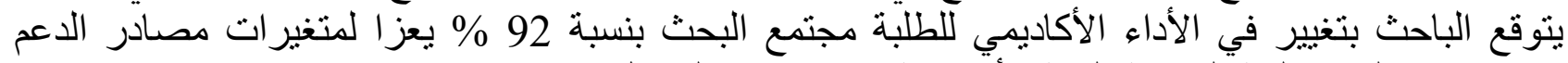

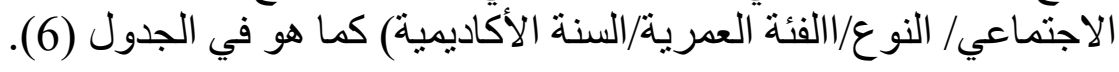
جدول (6) ملخص النموذج 
IJASOS- International E-Journal of Advances in Social Sciences, Vol. VI, Issue 18, December 2020

\begin{tabular}{|c|c|c|c|c|}
\hline الخطأ المعياري & الارتباط التربيعي المعدل & الارتباط التربيعي & الارتباط & النموذج \\
\hline 0,22 & 0,92 & 0,93 & 0,96 & 1 \\
\hline
\end{tabular}

نتائج تحليل الانحدار الخطي المتعدد التسلسلي باستخدام جدول المعاملات Coefficients يختبر جدول المعاملات معنوية معالم نموذج التحليل حيث أظهرت النتائج أكثر العو امل و المتغير ات تأثثر اً للتنبأ

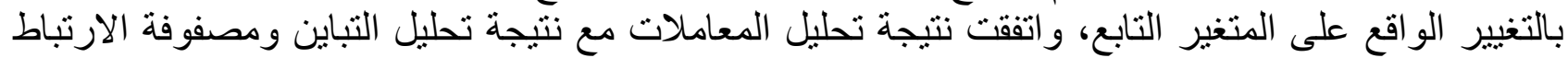

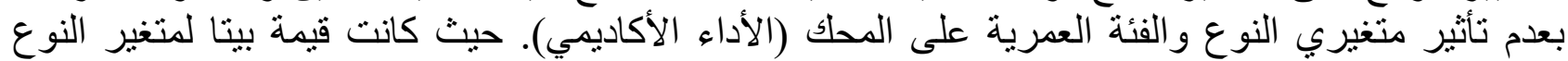

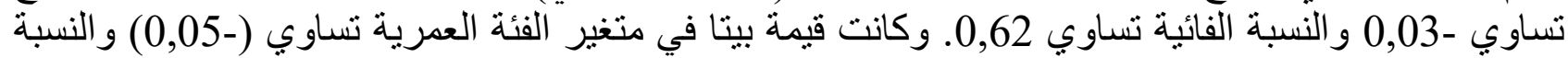

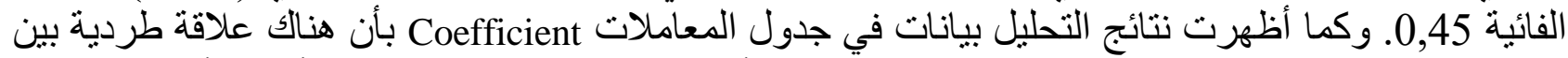

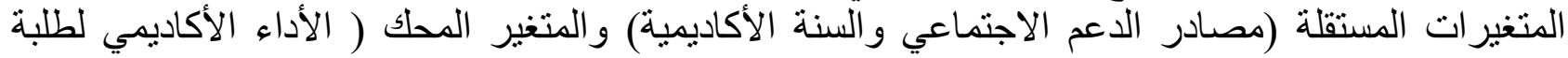

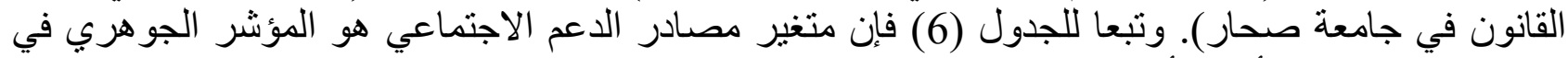
إحداث التغيير على الأداء الأكاديمي فكانت قيمة بيتا تساوي

الجدول (7) المعاملات

\begin{tabular}{|c|c|c|c|c|c|}
\hline \multirow{2}{*}{ النائية } & \multirow[t]{2}{*}{ 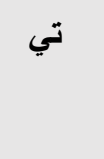 } & \multirow{2}{*}{ معاملات مقتنة } & \multicolumn{2}{|c|}{ معاملات غير مقتنة } & \multirow[t]{2}{*}{ النموذج } \\
\hline & & & الخطأ المعياري & بي & \\
\hline 0,19 & 1,35 & & 0,35 & 0,48 & المحك (الأداء) \\
\hline 0,00 & 16,10 & 0,95 & 0,17 & 0,92 & مصادر الدعم الاجتماعي \\
\hline 0,62 & $-0,51$ & $-0,03$ & 0,11 & $-0,05$ & النوع \\
\hline 0,45 & $-0,77$ & $-0,05$ & 0,07 & $-0,05$ & الفئة العمرية \\
\hline 0,58 & 0,57 & 0,04 & 0,07 & 0,04 & السنة الأكاديمية \\
\hline
\end{tabular}

الخاتمة:

استخدم الباحث الانحدار الخطي المتعدد البسيط وذللك لدراسة العلاقة بين مصادر الداعم الاجتماعي والأداء

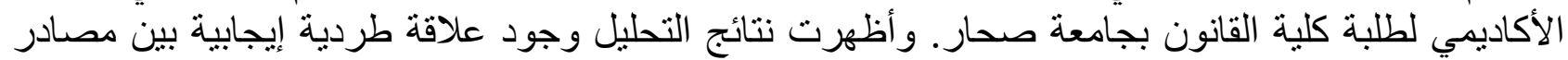

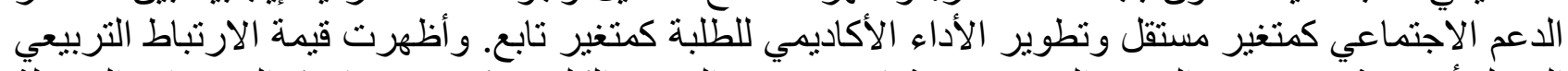

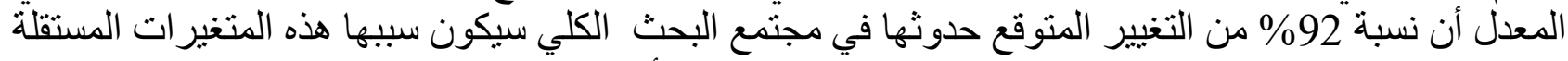

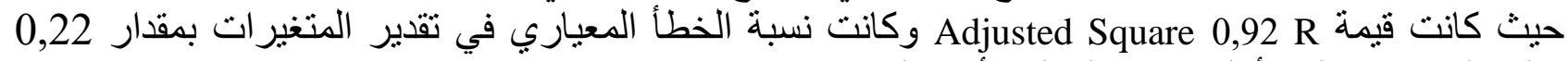
فكلما قلت نتيجة الخطأ المعياري قلة

النتائج:

من خلال ما تم استعر اضه في هذا البحث من إجابة على أسئلته من خلال التحليل العلمي، و التفسير المنطقي

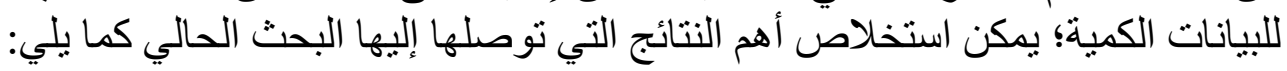
1- يعاني الطالب في كلية القانون في جامعة صحار من جملة من التحديات؛ كالتحديات المتعلقة بالأستاذ

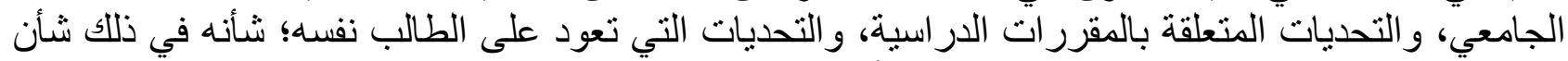

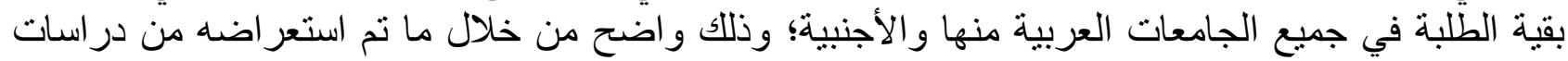
سابقة في ذات الإطار. 2- لمصادر الدعم الاجتماعي على اختلاف أنو اعها أهمية خاصة في تخفيف التحديات التي يعاني منها الطالب 
الجامعي.

3- تساهم مصادر الدعم الاجتماعي في شعور الطالب الجامعي بالاستقر ار النفسي؛ مما يزيد من مستوى تحصيله الأكاديمي.

التوصيات:

1- أهمبة التأكيد على الأدوار الأساسية التي ينبغي على الأستاذ الجامعي القيام بها تجاه طلبته إلى جانب مهامه

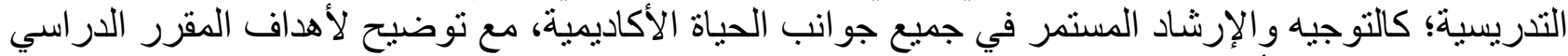

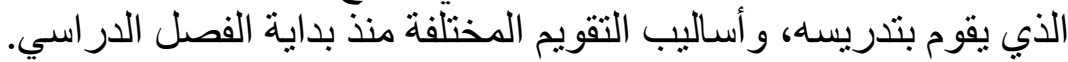

2- لا بد من وجود الرغبة الحقيقية للطلبة المتقدمين إلى كلية القانون لدر اسة القانون؛ إذ أن المو اد القانونية تتسم بنوع من التفصيل في مختلف جوانبها إلى جانب التدريب العملي في مختلف المؤسسات القانونية في فترة الإجازة الصبفية.

3- العمل على زيادة توفير مختلف الخدمات الاجتماعية والترفيهية للطلبة؛ لما له من دور فاعل في وصول

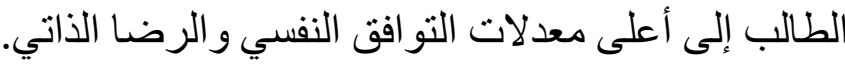
4ـ أهمية وجود مركز للإرشاد الأكاديمي يقلم خدماته الإرشادية لجميع الطلبة في مختلف الكليات و التخصصات. 5- استخدام نظام الحضور اليومي للطلبة بنظام البصمة؛ بحيث يتم تركيب أجهزة البصمة في كل قاعة در اسية؛

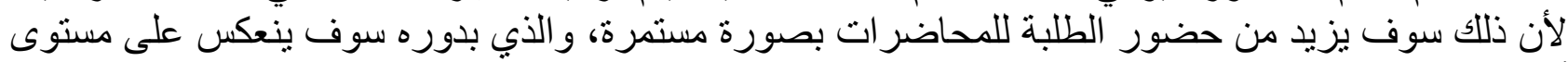

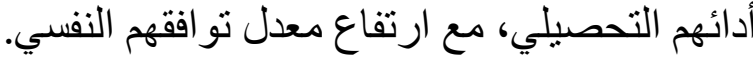
6ـ أهمية ربط الغياب اليومي للطالب عبر نظام القبول والتسجيل في الجامعة بهواتف أولياء أمور الطلبة لإبلاغهم عبر الرسائل النصية في حال تغيب أبنائهر عن المحاضرات بصورة فورية؛ مما سيحد ذلك من كثرة

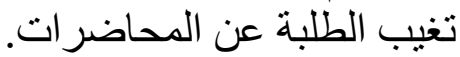

7- توضيح نظام تسجيل المقررات الدراسية في بداية كل فصل دراسي من قبل المرشدين الأكاديميين، مما

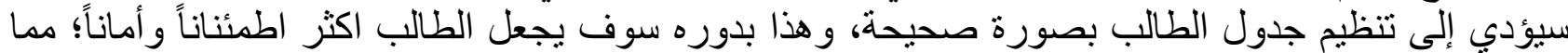
سيؤدي إلى انتظامه أكاديمياً.

8ـ تخصيص الأسبوع الأول لإقامة برنامج إرشادي للطلبة المقبولين في الكلية يتضمن لقاءً مفتوحاً مع عميد

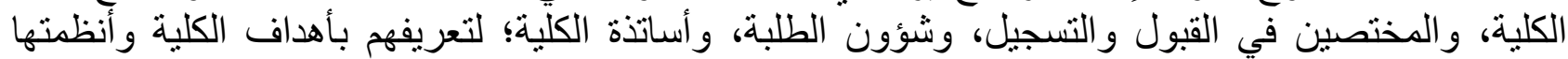
ولوائحها، والتعرف على احتياجاتهم والتحديات التي يواجهونها، وتزويدهم بالمعلومات والمهار وات واتهات اللازمة للطالب في حياته الجامعية.

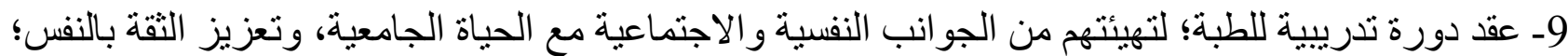

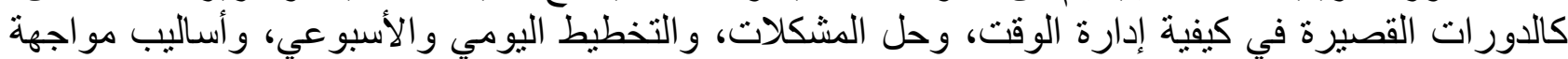

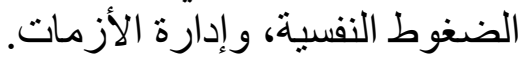

10 ـ أهمية مر اجعة الكلية للمقررات الدراسية، وطر ائق تدريسها بما يتو افق و الثورة الصناعية الر ابعة، و الذكاء

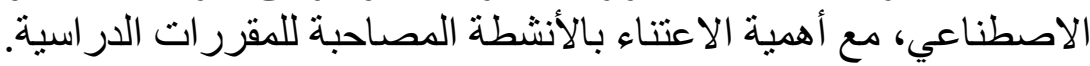
11- تبسيط نظام الإرشاد الأكاديمي المعمول به حالياً؛ بحيث يترك للمرشد الأكاديمي كتابة التقرير بطريقة الجدول المفتوح لضمان توجيه الطلبة ومساعدتهم في مختلف جو انب حياتهم، وتعريفهم بالطرق العلمية للمذاكرة و أنظمة ولوائح الجامعة.

12- التنسيق بين الجامعة ووز ارة التربية و التعليم لتقديم بر امج تو عوية ثابتة لطلبة الثاني عشر؛ لتهيئتهم للمرحلة

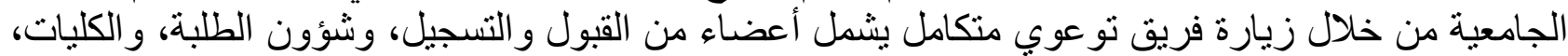
لعقد لقاءات مفتوحة مع الطلبة لثر حمد متطلبات المرحلة الجامعية، و النظام الجامعي. 
13- ربط تسجيل الطالب للمقرر ات، و الحذف و الإضافة بمرشده الأكاديمي؛ حتى يتمكن المرشد من الوقوف على الإنى

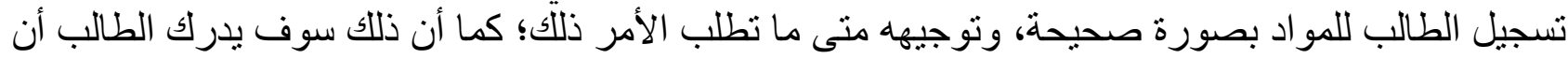

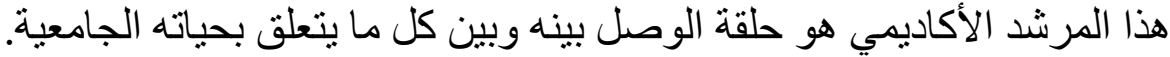

14ـ تخصيص المرشدين الأكاديميين ذوي الخبرة لطلبة السنة الأولى في بداية كل عام أكاديمي؛ باعتبار هم

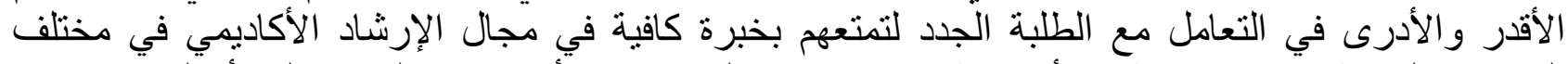

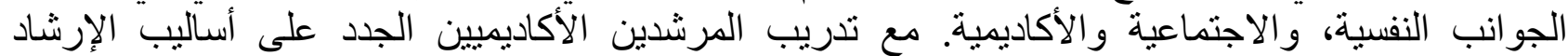

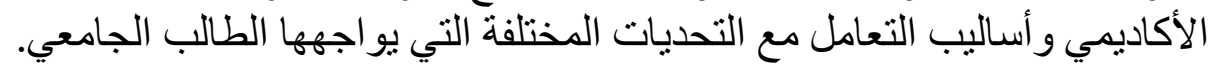
15ـ أهمية تبني الجامعة للار اسات العلمية الدورية، و التي تهتم بالطلبة منخفضي الأداء على مستوى كل كلية،

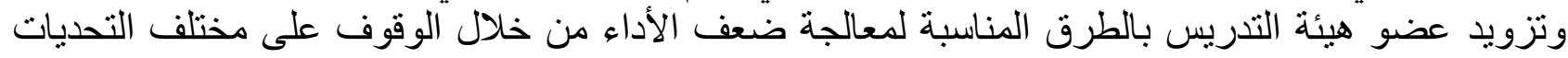
التي تو اجه الطلبة في الكلية، وسبل التغلب عليها. 16- التركيز عند تعبين أعضاء هيئة التدريس في الكلية على ذوي الخبرة العلمية والعملية؛ مع التركيز على التعلى كيفية التعامل مع الطلبة، وأساليب علاج مختلف التحديات الأكاديمية في صورة خطط إجرائية قابلة للتئية التفيذ و القياس و التقويم و التغذية الر اجعة. 17- تحديد مواعيد أسبوعية لمقابلة الأستاذ في مكتبه؛ ليتمكن من إنجاز مهامه الأكاديمية أولاً بأول؛ مع الأبه

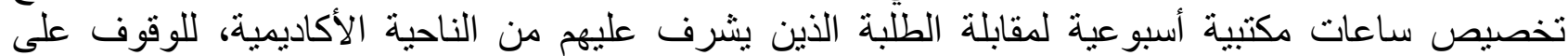
التحديات، ووضع الخطط العلاجية لها.

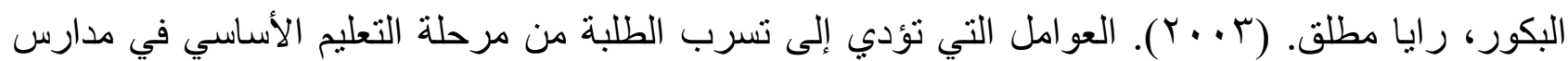
تربية الأغو ار من وجهة نظر مديري المدارس والمعلمين و المرشدين التربويين، رسالة ماجستير، جامعة الفاثر ، السودان.

بو بثيت، الجوهرة بنت إبر اهيم. (1 . . ب). المشكلات الأكاديمية التي تواجه طالبات كلية الدراسات التطبيقية

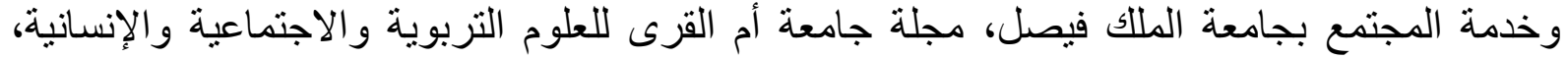

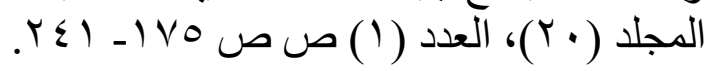

الجابري، نياف رشيد. (7 + . Y). محددات الأداء الأكاديمي لطلاب وطالبات جامعة طيبة في المملكة العربية

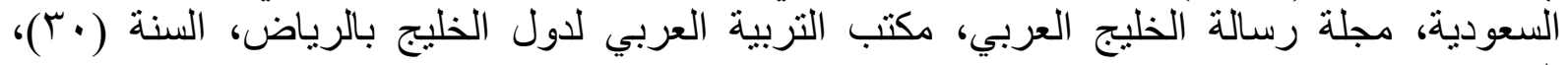

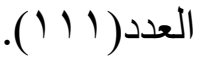

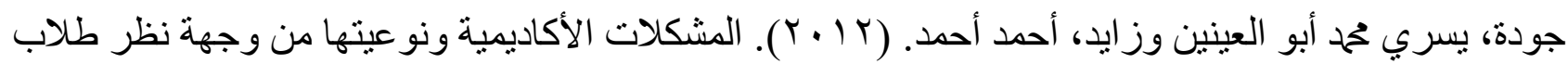

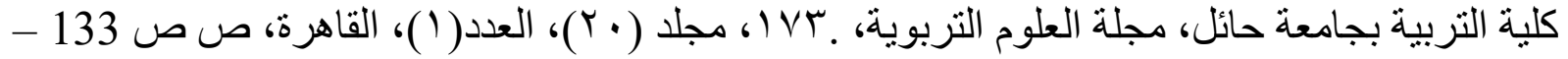

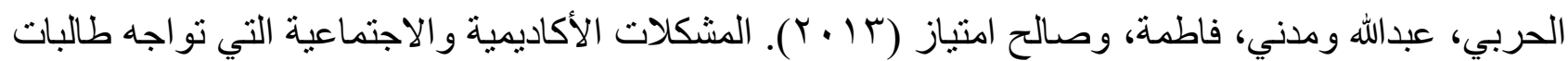

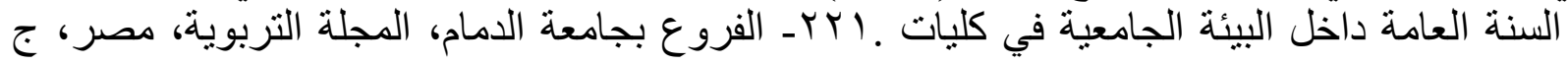

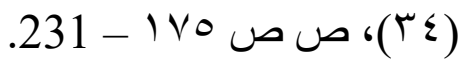

حمادة، عبد المحسن الصاوي، محه وجيه (ع . . ب). العوامل الكامنة وراء تعثر الطلاب المنذرين بجامعة الكويت، مجلة در اسات الخليج والجزيرة العربية، العدد (112)، مجلس النشر العلمي، جامعة الكويت.

درويش، زينب عو اد والحريبي، فاطمة (س (Y). المثكلات الأكاديمية لدى طالبات جامعة الأمير سلمان

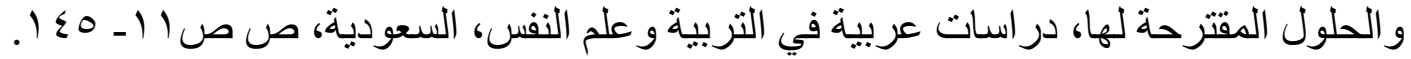
الدمياطي، سلطانة إبر اهيم (9 . . ب). المشكلات الأكاديمية لطالبات جامعة طيبة و علاقتها بمستوى الأداء: در اسة 
ميدانية، ندوة التعليم العالي للفتاة: الأبعاد و التطلعات، جامعة طيبة، المدينة المنورة، ص ص 96 ـ • ؛ 1.

الز هر اني، حسن على (0 . . Y). المشكلات النفسية والاجتماعية و التعليمية لدى عينة من طلاب كليات المعلمين

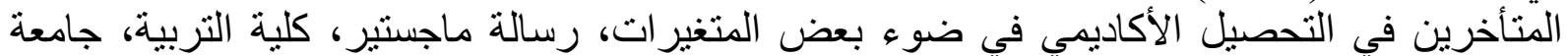

الملك سعود.

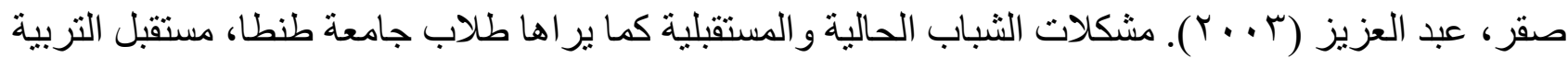

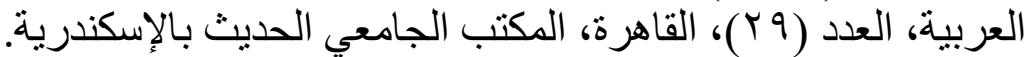

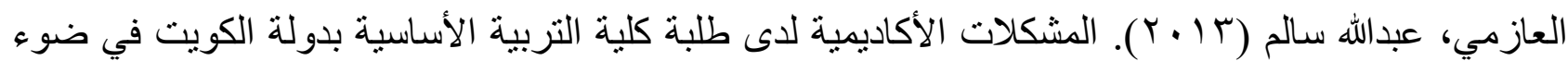

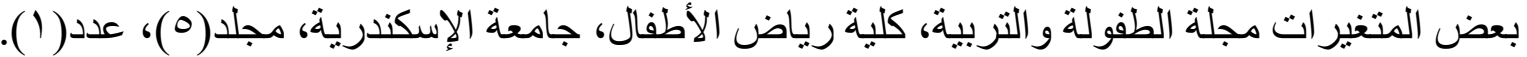

العقيلي، عبد المحسن العقيلي أبو الهاشم، السيد محم (9 . ب). المشكلات الأكاديمية لدى طلاب الكليات الإنسانية

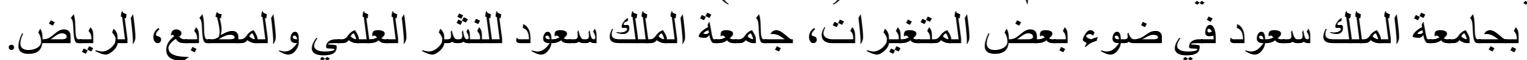

علي، علي عبدالسلام (1997). الدعم الاجتماعي ومواجهة أحداث الحياة الضاغطة كما تدركها العاملات

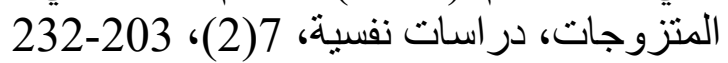

مرزا، هند محمود (10 م ب). المشكلات الأكاديمية والإدارية للطلاب المستجدين في فرع الجامعة العربية

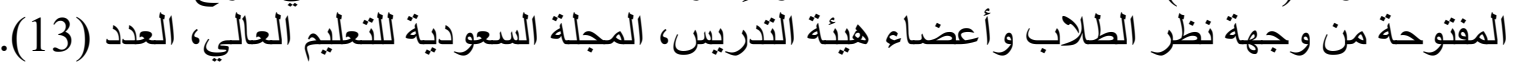

ملكوش، رياض (2000). الدعم الاجتماعي والتكيف الطلابي لدى طلبة الجامعة الأردنية، دراسات العلوم

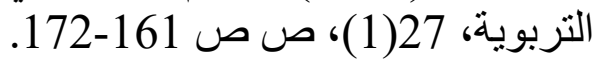

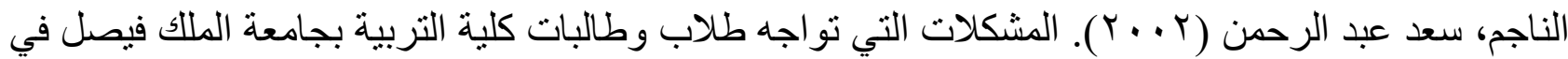

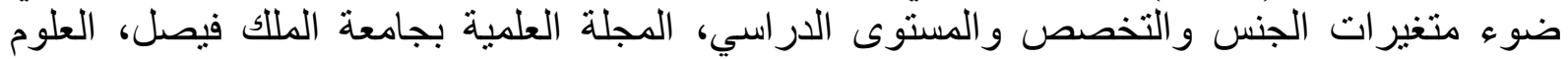

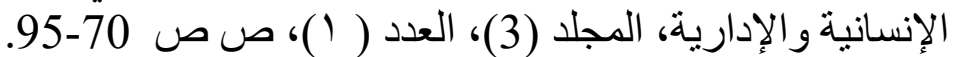

\section{ARABIC REFERENCES IN ROMAN ALPHABET}

Albikur, Rayaan Matluq. (2003). Aleawamil Alty Tuadiy 'lilaa Tasarub Altalabat Min Marhalat Altaelim Al'asasii $\mathrm{Fi}$ Madaris Tarbiat Al'aghwar Min Wijhat Nazar Mudiri Almadaris Walmuealimin Walmurashadin Alturbuiiyna, Risalat Majstir, Jamieat Alfashiri, Alsuwdan.

Bu Bashit, Aljawharat Bnt 'librahim. (2005). Aleawamil Almuadiyat 'lilaa Tadaniy Almueadal Altarakumii Lilttalibat Kama Taraha Talibat Kuliyat Altarbiat Waleulum Alziraeiatu, Almajalat Aleilmiat Lijamieat Almalik Faysal, Aleulum Al'iinsaniat Wal'iidariiti, Mj(6), E (1) S.S 191 - 248.

Bu Bashit, Aljawharat Bnt 'librahim. (2008). Almushkilat Al'akadimiat Alty Tuajih Talibat Kuliyat Aldirasat Altatbiqiat Wakhidmat Almujtamae Bijamieat Almalik Faysal, Majalat Jamieatan 'Ama Alquraa Lileulum Altarbawiat Walaijtimaeiat Wal'iinsaniati, Almajalid (20), Aleadad (1) S.S 175- 241.

Aljabiri, Nayaf Rushid. (2006). Muhadadat Al'ada' Al'ukadimii Litalab Watalibat Jamieat Tayibat $\mathrm{Fi}$ Almamlakat Alearabiat Alsaeudiati, Majalat Risalat Alkhalij Alearabii, Maktab Altarbiat Alearabii Lidual Alkhalij Bialrayadi, Alsana (30), Aledd(111).

Judut, Yusri Muhamad 'Abu Aleinayn Wazayid, 'Ahmad 'Ahmid. (2012). Almushkilat Al'akadimiat Wanaweiatuha Min Wijhat Nazar Tullab Kuliyat Altarbiat Bijamieat Hayil, Majalat Aleulum Altarbuiatu, .173, Mujalad (20), Aledd(1), Alqahrt, S.S 133 - 173.

Alharbi, Eabdallah Wamadani, Fatimat, Wasalih Aimtiaz (2013). Almushkilat Al'akadimiat Walaijtimaeiat Alty Tuajih Talibat Alsanat Aleamat Dakhil Albiyat Aljamieiat Fi Kliat .221- Alfurue Bijamieat Aldamam, Almajalat Altarbuiati, Misr, J (34), S.S 175 - 231.

Himadat, Eabd Almuhsin Alsawi, Muhamad Wajih (2004). Aleawamil Alkaminat Wara' Taethur Altullab Almundharin Bijamieat Alkuayti, Majalat Dirasat Alkhalij Waljazirat Alearabiat, Aleadad (112), Majlis Alnashr Alealmii, Jamieat Alkuayt.

Daruish, Zaynab Ewad Walharibi, Fatima (2013). Almushkilat Al'ukadimiat Ladaa Talibat Jamieat Al'amir Salman Walhulul Almuqtarahat Laha, Dirasat Earabiat Fi Altarbiat Waealam Alnafsi, Alsaeudiati, S.S. $11-145$. 
Aldamiatiu, Silitanat 'librahim (2009). Almushkilat Al'akadimiat Litalibat Jamieat Tayibat Waealaqatuha Bimustawaa Al'ada': Dirasat Midanit, Nadwat Altaelim Aleali Llftat: Al'abead Waltatalueat, Jamieat Tayibat, Almadinat Almunawarat, S.S. 96 - 140.

Alzahrani, Hasan Ealaa (2005). Almushkilat Alnafsiat Walaiitimaeiat Waltaelimiat Ladaa Eayinat Min Tullab Kaliyat Almuealimin Almuta'akhirin Fi Altahsil Al'ukadimii Fi Daw' Bed Almutaghayirati, Risalat Majstir, Kuliyat Altarbiat, Jamieat Almalik Sueud.

Saqr, Eabd Aleaziz (2003). Mushkilat Alshabab Alhaliat Walmustaqbaliat Kama Yaraha Tullab Jamieat Tuntaan, Mustaqbal Altarbiat Alearabiati, Aleadad (29), Alqahiratu, Almaktab Aljamieiu Alhadith Bial'iiskandariat.

Aleazimi, Eabdallah Salim (2013). Almushkilat Al'ukadimiat Ladaa Tlbt Kuliyat Altarbiat Al'asasiat Bidawlat Alkuayt Fi Daw' Bed Almutaghayirat Majalat Altufulat Waltarbiati, Kuliyat Riad Al'atfali, Jamieat Al'iiskandriat, Mjld (5), Eidd(1).

Aleaqili, Eabd Almuhsin Aleaqili 'Abu Alhashm, Alsyd Muhamad (2009). Almushkilat Al'ukadimiat Ladaa Tullab Alkuliyat Al'iinsaniat Bijamieat Almalik Sueud Fi Daw' Bed Almutaghayirati, Jamieat Almalik Sueud Lilnashr Aleilmii Walmatabiei, Alriyad.

Ealay, Eali Eibdialslam (1997). Aldaem Alaijtimaeiu Wamuajahat 'Ahdath Alhayat Alddaghitat Kama Tudrikuha Aleamilat Almutazawijati, Dirasat Nafsiat, 7(2), 203-232

Marza, Hand Mahmud (2015). Almushkilat Al'ukadimiat Wal'iidariat Liltalaab Almustajidiyn Fi Fure Aljamieat Alearabiat Almaftuhat Min Wijhat Nazar Altullab Wa'aeda' Hayyat Altadrisi, Almajalat Alsewdyt Liltaelim Aleali, Aleadad (13).

Malkush, Riad (2000). Aldaem Alaijtimaeiu Waltakif Altalabiu Ladaa Tlbt Aljamieat Al'urduniyati, Dirasat Aleulum Altarbiwiat, 27(1), S.S 161-172.

Alnajim, Saed Eabd Alrihmun (2002). Almushkilat Alty Tuajih Tullab Watalibat Kuliyat Altarbiat Bijamieat Almalik Faysal Fi Daw' Mutaghayirat Aljins Waltakhasus Walmustawaa Aldarasii, Almajalat Aleilmiat Bijamieat Almalik Faysali, Aleulum Al'iinsaniat Wal'iidariat, Almujalid (3), Aleadad (1), S.S 70-95.

\section{REFERENCES}

Burke, J. \& Greenglass, E. (1993). Work stress role conflict, social support, and Psychological burnout among teachers, Psychological Reports, 73,371-380.

Cecil, A. \& Forman, G. (1990), Effect of stress inoculation training and coworker support groups on teacher's stress, Journal of School Psychology, 28, 105-118.

Doygun, O. and Gulec, S. (2012) "The problems faced by university students and proposals for solution," Procedia - Social and Behavioral Sciences, 47. 1115-1123.

Dukkar, K. (1995). Psychological Problems in Pennsylvania State University. Psychology Journal, Vol.21, pp.40-60.

Griffith, J., Steptoe, A, \& Cropley, M. (1999). An investigation of coping strategies associated with job stress in teachers, British Journal of Educational Psychology,69, 517-531.

Kenneth, M (1995). Career, Personal and Educational Problems of Community College Students. Severity \& Frequency. Research and Teaching in Development Education, Vol. 32, No.4, pp 270-278.

Norwich, B. \& Daniels, H. (1997). Teacher support teams for special educational needs in primary schools: evaluating a teacher-focused support scheme, Educational Studies, 23(1), 5-24.

Norwich, Brahm \& Daniels, Harry (1997). Teacher Support Teams for Special Educational Needs in Primary Schools: evaluating a teacher-focused support scheme, Educational Studies, Volume 23, Issue 1, Pp5-24.

Russel, W., Altmaier, E, \& Velzen, V. (1987). Job-related stress, social support, and burnout among classroom teacher, Journal of Applied Psychology, 22(2), 269-274.

Senel, P., Consuelo, A., Robin, B., \& Stewart, P. (2001). Adjustment Issues of Turkish College Students Studying in the United States, College Student Journal. 